\title{
RESERVE PRICE EFFECTS IN AUCTIONS: ESTIMATES FROM MULTIPLE RD DESIGNS*
}

SYNGJOO CHOI
LARS NESHEIM

MARCH 2015

\author{
IMRAN RASUL ${ }^{\dagger}$
}

\begin{abstract}
We present evidence from 260,000 online auctions of second-hand cars to identify the impact of public reserve prices on auction outcomes. We exploit multiple discontinuities in the relationship between reserve prices and vehicle characteristics to present causal RD estimates of reserve price impacts. We find an increase in reserve price decreases the number of bidders, increases the likelihood the object remains unsold, and increases expected revenue conditional on sale. We then combine these estimates to calibrate the reserve price effect on the auctioneer's ex ante expected revenue. This reveals the auctioneer's reserve price policy to be locally optimal.
\end{abstract}

Keywords: auctions, regression discontinuity, reserve price.

JEL Classification: D44, L11, L62.

*We gratefully acknowledge financial support from the UK ESRC through CeMMAP (ESRC grant RES-589-280001) and ELSE. We thank Florian Englemaier, Philippe Jehiel, Jinwoo Kim and numerous seminar participants for valuable comments. We are very grateful to all those involved in supplying this data to us. This paper has been screened to ensure no confidential information is revealed All errors remain our own.

${ }^{\dagger}$ All authors are at the Department of Economics, University College London, Drayton House, 30 Gordon Street, London WC1E 6BT, United Kingdom. Choi is also affiliated with the Department of Economics, Seoul National University, South Korea. E-mails: syngjoo.choi@ucl.ac.uk; l.nesheim@ucl.ac.uk, i.rasul@ucl.ac.uk. 


\section{Introduction}

Online auctions are an important trading mechanism in modern economies. eBay alone has 81 million active users worldwide and auctions a billion objects annually [eBay 2009]. As data from auction settings has become accessible, especially from online auction environments, there has been a surge in empirical analysis testing whether the behavior of buyers and sellers is consistent with auction theory [Bajari and Hortacsu 2004]. We contribute to this empirical literature by presenting evidence from 260,000 online auctions of second-hand cars that took place between January 2003 and November 2008. We identify the impact of a common feature of online and o- ine auctions - public reserve prices - on a rich set of auction outcomes. ${ }^{1}$

To establish causality, we present evidence from multiple regression discontinuity (RD) research designs, an empirical method that has not been used in the earlier literature to test the predictions of auction theory. Guided by theory, we first identify the impact of reserve prices on various standard margins of bidder's behavior such as their entry into auctions, bidding behavior within the auction, and ultimately the winning bid. We then combine these estimates to shed light on whether the reserve prices set by the auctioneer indeed maximize her ex ante expected revenue. At a final stage we exploit our rich data to provide new insights that have not previously been documented in the empirical auctions literature, such as the impact of reserve prices on: (i) bidder's search behavior; (ii) the composition and characteristics of bidders. This new evidence helps shed light on how to best characterize this environment in terms of whether bidders endogenously enter auctions, and whether they hold symmetric valuations or not.

Our analysis has broad relevance in three regards. First, car sales through auctions form an important share of the market: the value of cars sold via auction in the US was $\$ 89 \mathrm{bn}$ in 2007 , and used car dealers filled over 30\% of their inventory via auctions [Roberts 2013]. Second, the auction mechanism used in our setting, an open ascending second-price auction that allows proxy bidding, is widely suggested to be the most prevalent online auction format [Bajari and Hortacsu 2004]. Third, the specific auction design feature we study, reserve prices, is commonly observed in online and o- ine formats.

The first set of outcomes we study are motivated by the theoretical auction literature. These relate to the impact of reserve prices on winning bids, the number of entrants - i.e. the number of bidders that place at least one bid, and the probability the object is sold. ${ }^{2}$ Theory suggests reserve price impacts on these margins depend on three factors: (i) whether bidders have private or common valuations of the auctioned object; (ii) whether bidder entry is exogenous or endogenous;

\footnotetext{
${ }^{1}$ The reserve price is the minimum amount the auctioneer will accept for the auction to end with a sale. All the auctions we study have public reserve prices. Vincent [1995] and Rosenkranz and Schmitz [2007] provide theoretical explanations for when reserve prices should be public or secret. Katkar and Reiley [2006] provide empirical evidence on the impact of public versus secret reserve prices on seller revenues.

${ }^{2}$ With the second price auction format we study, the winning bid is the higher of, the second highest bid and the reserve price.
} 
(iii) whether the reserve price signals the auctioneer's private information on the true value of the auctioned object.

In exogenous entry models, predictions about the impact of reserve prices on these outcomes are robust with regard to whether bidders have private, affiliated or common values for the object [Myerson 1981, Riley and Samuelson 1981, Milgrom and Weber 1982] and to whether the reserve price conveys a signal of the object's value to buyers [Cai et al. 2007]. As is intuitive, in this class of exogenous entry models, a higher reserve price discourages entry of marginal bidders, decreases the likelihood the object is sold, and increases winning payments conditional on sale.

Theoretical predictions on reserve price impacts are less clear-cut in endogenous entry models [Levin and Smith 1994, Tan and Yilankaya 2007]. Analogous to exogenous entry models, a higher reserve price discourages entry of both potential and actual bidders and decreases the probability of sale. However, a higher reserve price might decrease winning payments through its adverse impact on entry. Overall, there is an ambiguous impact of the reserve price on the expected revenue conditional on sales. There might be circumstances in which it is optimal for the auctioneer to set no reserve [Levin and Smith 1994, Vincent 1995, Bulow and Klemperer 1996, Horstmann and LaCasse 1997]. We are not aware of any models that study auction environments with endogenous entry in which the reserve price signals the object's value. We would expect the impact of the reserve price to be ambiguous on all three margins in such settings.

Table 1 summarizes the theoretical predictions of the impact of reserve prices on these three margins: winning bids conditional on sale, the number of entrants, and the probability the object is sold. To be clear, theory provides ambiguous predictions on the impact of reserve prices on these margins. Hence our first contribution is to provide credible estimates of the causal impact of reserve prices on these margins and to begin to shed light on the most parsimonious class of model that best characterizes this complex auction environment. ${ }^{3}$

Existing evidence based on laboratory studies and structural models suggests reserve prices might be an important determinant of seller revenues (these literatures are reviewed in Kagel 1995 and Paarsch and Hong 2006 respectively). A nascent literature is now emerging that uses natural field experiments to measure reserve price effects [Reiley 2006, Brown and Morgan 2009, Ostrovsky and Schwarz 2009]. ${ }^{4}$ We build on and complement this literature by providing the first evidence

\footnotetext{
${ }^{3}$ All the theory papers summarized in Table 1 assume symmetry of bidders. Bidder asymmetry is another potentially important dimension to consider in the analysis of reserve price impacts. Roberts and Sweeting [2011] are one of the few studies we are aware of that allows for bidder asymmetry and endogenous entry to compare the potential values of setting an optimal reserve price versus increasing competition within an auction. It is, however, unclear what reserve price impacts one should expect on the three margins we study given the multiplicity of equilibria. Our results help shed light on whether bidder asymmetry plays some role in this auction setting.

${ }^{4}$ The evidence from field experiments also reinforces the notion that reserve prices are a relatively important determinant of revenues in online auctions relative to some other auction design features [Bajari and Hortacsu 2004]. For example, Brown and Morgan [2009] find that while reserve prices significantly increase winning bids, variation in auction ending rules that allow for late bidding, have no appreciable effect on revenues or the number of entrants. Of course there are other aspects of auction design that have significant effects on revenues. Chief among these is the precise auction format, as strongly suggested by the evidence in Athey et al. [2011] from o- ine
} 
on reserve price impacts measured using quasi-experimental regression discontinuity estimates.

There are three key distinctions between our analysis and the earlier experimental evidence on reserve price effects from lab and field settings. First, we study reserve price impacts for relatively high stakes objects. ${ }^{5}$ Second, we provide reserve price impacts not just on those margins of bidder behavior emphasized by theory, but we are able to combine these estimates with data on re-auctioned vehicles to calibrate the overall impact of reserve prices on the auctioneer's $e x$ ante expected revenue. This sheds light on whether the auctioneer behaves optimally and sets her reserve price at the locally optimal level. Third, we exploit unique aspects of our data to provide evidence of reserve price impacts on novel margins of behavior to delve deeper into understanding how best to characterize this auction environment. First, using web browsing histories of individuals on the auction website we determine the impact on the number of potential bidders, namely those individuals who draw a private signal from their valuation distribution and decide whether to bid or not. This provides evidence on whether bidder entry is endogenous. Second, exploiting data from bidder histories with the auctioneer dating back to January 2003, we study how bidder characteristics change with reserve prices. This again sheds light on whether bidder entry is endogenous and whether bidders are asymmetric either in terms of valuations or information about objects' true values.

To provide credible estimates of reserve price impacts, we exploit discontinuities in the relationship between reserve prices and vehicle characteristics. There are multiple regression discontinuities to exploit in our data. As described in more detail later, the discontinuities in reserve prices differ across distinct classes of vehicle, and change over time within vehicle classes. In total, we exploit four discontinuities in reserve price that vary in magnitude and sign. ${ }^{6}$ Moreover, given the change in reserve prices over time, we are also able to present difference-in-difference estimates of the same reserve price effects that exploit the time variation in how reserve prices are set. This allows us provide greater external validity to our results by estimating reserve price effects over a wide range of reserve prices, not just those local to the discontinuities, which is often cited as the main limitation of RD designs.

Our main results are as follows. First, in terms of the reserve price impacts on the three standard margins emphasized by theory and highlighted in Table 1, an increase in reserve price: (i) decreases the number of actual bidders; (ii) decreases the likelihood the object is sold; (iii)

timber auctions on the relative effects of sealed bid and open auctions.

${ }^{5}$ Relative to most other experimental studies of online reserve price effects, the objects we consider are high stakes items. Over our entire sample, the mean value of a vehicle sold is $£ 793$ but there is also considerable variation in winning valuations: the 90th (10th) percentile of winning bid distribution is $£ 1680$ (£50). Reiley [2006] presents field experiment evidence on reserve prices for collectible trading cards where average winning bids are $\$ 100$. Brown and Morgan [2009] present evidence on reserve price effects from a field experiment on online coin auctions across auctioneers where average winning bids are between $\$ 40$ and $\$ 60$.

${ }^{6}$ In the Appendix we describe a series of checks on the credibility of the RD design. We divide these checks into three types: (i) whether discontinuities in auction outcomes at the cut-off remain conditional on observables; (ii) whether the assignment variable is smooth around the discontinuity or appears to have been manipulated by the seller; (iii) whether there is endogenous sorting of bidders on either side of the cut-off. 
increases expected revenue conditional on the object being sold. All of these findings are robust to restricting attention to auctions in which at least two bidders enter and place bids. Mapping these findings back to theory, we note that we can rule out a benchmark second-price style model of bidders holding IPV with exogenous entry and bidding their true valuation. This is because in that model the winning bid is independent of the reserve price if the reserve price is not binding. Our findings further imply that if bidder entry is endogenous, higher reserve prices do not curtail entry to such an extent so as to decrease winning bids conditional on sale. Hence, it is unlikely that the auctioneer would find it optimal to set no reserve in this setting. This implication is then confirmed as we bring together these various estimates to explicitly calibrate the overall impact of reserve prices on the auctioneer's ex ante expected revenue. Our results reveal that the reserve price policy followed by the auctioneer is locally optimal in that a small change in reserve price would not significantly change the seller's expected revenue.

Finally, we provide the first evidence on impacts of reserve prices along the following margins. First, as reserve prices rise, the number of potential bidders (the number who click on and view an auction webpage) falls. This effect is however far smaller in magnitude than the reserve price effect on the number of actual entrants (those who place a bid). Second, averaging across all entrants, only more experienced and historically more successful bidders remain in the auction at higher reserve prices. If bidder valuations correlate to bidder characteristics, this result suggests that entry into auctions is endogenous. In consequence, the valuation of bidders that enter the auction differ from those that could have potentially entered the auction. Along both margins - bidder experience and winning histories - the characteristics of actual winners are less sensitive to the reserve price than the average bidder. Hence as is intuitive, the evidence suggests auction winners are not the marginal entrant, which again is indicative of endogenous entry and asymmetries across bidders. Taken together, these margins are informative for the development of future theory, and provide a basis from which, in future work, to construct and estimate a structural model of bidder's behavior in this setting.

The paper is organized as follows. Section 2 discusses the auction environment, data sources, descriptive evidence, and the RD design. Section 3 presents our RD estimates on standard margins of behavior. Section 4 focuses on the seller's behavior and calibrates her first order condition for expected revenue maximization to shed light on whether reserve prices are set at the locally optimal level. Section 5 estimates reserve price effects on more novel margins of bidder behavior. Section 6 concludes. The Appendix provides evidence on the credibility of the RD design, robustness checks on our baseline results, and presents difference-in-difference estimates of the same reserve price effects that exploit the time variation in how reserve prices are set. This allows us to provide greater external validity to our results by estimating reserve price effects over a wide range of reserve prices, not just those local to the discontinuities. 


\section{Setting, Data and Descriptives}

\subsection{The Setting}

We analyze data from a UK based auctioneer on 260,000 online auctions that occurred between January 2003 and November 2008. The objects for auction are second-hand vehicles that have been salvaged from an insurance firm most after having been involved in an accident of some sort. The auction mechanism used is an open ascending second-price auction allowing proxy bidding. ${ }^{7}$ Potential bidders need to register with the auctioneer to browse the inventory of auctions and enter any specific auction. Most bidders are professional buyers and have much experience with the auction format and the use of reserve prices. We focus on identifying the causal impact of reserve prices on auction outcomes holding constant all other auction design features. ${ }^{8}$

Most of the vehicles in our sample had been involved in an accident. The nature of the accidents varies, ranging from very minor accidents for vehicles that are ready to go back on the road, to vehicles that are written-off and can only be utilized for spare parts or scrap. In the UK automobile salvage market, vehicles are grouped into four categories based on the degree of damage. The categories are defined by the Association of British Insurers (ABI) and standards for classification are published. ${ }^{9}$ Our dataset contains information on auctions of cars in three of the four categories, referred to as Categories B, C and D.

Two steps are taken to classify each vehicle into a category. First, the pre-accident value for the vehicle $(P A V)$ is independently assessed by engineers from the insurance firm supplying the vehicles. These correspond closely to published secondhand vehicle values from the main UK sources (Parker's Car Price Guide or Glass's Guide to Car Values) and so are not subject to manipulation. Cars can then be categorized as follows. Category-B (Cat-B) cars are so structurally damaged or devoid of parts that it is not possible to repair the car economically or safely. Such cars are purchased essentially for their scrap metal value. Category-C (Cat-C) cars are damaged

\footnotetext{
${ }^{7}$ Bajari and Hortacsu [2003] describe proxy bidding in eBay auctions for coins. Borrowing from their description, when a bidder submits a proxy bid, she is asked by the auctioneer to state the maximum amount she is willing to pay for the object. Suppose the reserve price is $£ 10$, the bid increment is $£ 5$, and the first bidder, bidder A, places a proxy bid of $£ 100$. The highest bid of bidder $\mathrm{A}$ is then initially set to the reserve price. If a new bidder enters with a proxy bid of $£ 25$, i.e. above the reserve and below $£ 100$, the highest bid of bidder A is re-set to $£ 30$ ( 225 plus the bid increment). If the highest bid reaches above bidder A's proxy bid, she can always place a new proxy bid. At the auction close, the highest bidder wins and pays the second-highest proxy bid plus one bid increment.

${ }^{8}$ In our sample period $79 \%$ of winning bidders are professionals, namely sole traders, companies or partnerships that predominantly purchase vehicles for resale. The remaining winners are private buyers. The median bidder has been registered with the auctioneer for three years. Such bidders are unlikely to suffer from the winner's curse, as has been found for more inexperienced bidders in online common value settings. Other auction design features, such as the auction length, bid increments, and whether late-bidding automatically extends the auction, do not vary discontinuously with the reserve price discontinuities we exploit, nor do they vary at the same time as exploited for the DD estimates described in the Appendix.

${ }^{9}$ Salvage categories were developed by the Association of British Insurers, vehicle recyclers, the UK Driver and Vehicle Licensing Agency (DVLA) and the UK police force in an effort to curb vehicle crime in the UK [Association of British Insurers 2007].
} 
to the extent that the retail cost of repair to the car is estimated to exceed the retail $P A V$. Hence it is not economically viable to repair the car and return it to the road. Such cars are purchased for their spare part value. Finally, Category-D (Cat-D) cars have suffered minor or no damage and the retail cost of repair to the vehicle does not exceed the retail $P A V$. Such cars are mostly bought by professional dealers or private buyers, to go back on the road.

This categorization opens up the possibility of measuring the impact of reserve prices on auction outcomes across distinct car markets for each vehicle category that significantly differ in: (i) the expected number of entrants; (ii) the underlying value of the item to the seller; (iii) resale possibilities and hence whether bidder valuations are best thought of as being private or common.

\subsection{Data Sources}

We combine various data sources for our analysis. The first provides details of all auctioned vehicles and contains information on: (i) vehicle characteristics such as make and model, transmission, engine size, shape, mileage, whether the keys are available, a detailed description of any damage etc.; (ii) auction characteristics such as the date of the auction, the bid increment, the salvage yard at which the vehicle is held and can be viewed etc. In an OLS regression framework for first time auctions, these observable vehicle and auction characteristics explain $65 \%$ of the variation in winning bids in Cat-B auctions, and over $80 \%$ of the variation in Cat-C and Cat-D auctions.

Our second data source relates to the web browsing histories of all bidders since January 2007. This allows us to track which auctions each registered bidder views, the number of times they view a given auction's web page, and the time at which they viewed. We use this to construct measures of the number of potential bidders in an auction. We use this information to measure whether the number of potential bidders varies with the reserve price, as would be the case in any model of endogenous bidder entry.

Our third data source is at the bid-bidder-auction level. For each auction we observe the sequence of bids placed by all bidders, not just the winner. We observe the bid value, the time at which it was placed, whether it was a proxy bid and so forth. Each bidder has a unique identifier that we match with bidder registration data. This details when each bidder first registered with the auctioneer and the type of bidder (partnership, company, private buyer etc.). We use this to construct bidder histories with the auctioneer based on their behavior since January 2003. For example, for bidder $j$ on date $t$ we define her 'win-rate' as,

$$
w_{j t}=\frac{\# \text { auctions won between January } 2003 \text { and } t}{\text { \#auctions entered since January } 2003} .
$$

We define analogous win-rates for specific categories of vehicles, as bidders tend to specialize by category. We use these bidder histories to construct proxies for bidder heterogeneity in any given auction and to estimate how the composition of all bidders in general, and winners in particular, 
changes with (discontinuous) changes in the reserve price. This helps shed light on whether bidder entry into auctions is endogenous and bidders are heterogeneous.

Our working sample covers 258,068 first time auctions, 55\% of which are for Cat-C vehicles. There are 6200 registered and active bidders over this period.

\subsection{Reserve Price Regimes}

The precise algorithm to set the reserve price in auction $i\left(R_{i}\right)$ is based discontinuously on the car's pre-accident value, $P A V_{i}$. Three points are of note. First, $P A V_{i}$ is determined by engineers from the insurance firm that supplies the vehicle to the auctioneer. As mentioned before, these correspond closely to published values from sources such as Glass's Guide to Car Values. Importantly for the RD design, this value is not subject to manipulation, and moreover the engineers have no incentives to attempt such manipulation as their payoffs do not depend on the $P A V_{i}$ nor on the revenues raised from vehicle auction. In the Appendix we provide further evidence in support of this underlying identifying assumption of non-manipulation of $P A V_{i}$.

Second, the $P A V_{i}$ is not revealed to potential bidders, nor is the algorithm mapping $P A V_{i}$ to $R_{i}$. When potential bidders browse the auction website they first observe the set of auctions active that day. The median number of active auctions on a given day is 189. At this stage, potential bidders know only the vehicle model being auctioned and its salvage category. If a potential bidder then chooses to view a specific auction web page, they observe: (i) detailed vehicle characteristics, but excluding $P A V_{i}$; (ii) auction characteristics such as start and close times, and the reserve price; (iii) the current highest bid and the entire history of highest bids and when they were placed. No information is provided on bidder identities or the number of bidders. ${ }^{10}$

Third, the relationship between $R_{i}$ and $P A V_{i}$ differs across vehicle categories $\mathrm{B}, \mathrm{C}$ and $\mathrm{D}$. Within a category, the mapping between $R_{i}$ and $P A V_{i}$ also varies over time. Between 2003 and 2008 we observe six distinct reserve price regimes across car category and time, as summarized in Table 2. Column 1 shows that for Cat-C cars, from 10th July 2006 to 17th November 2008, the reserve price was a discontinuous function of $P A V_{i}$. In particular, $R_{i}=£ 40$ if $P A V_{i}<£ 1500$, and $R_{i}=.08 \times P A V_{i}$ if $P A V_{i} \geq £ 1500$. This induces a discontinuity in $R_{i}$ from $£ 40$ to $£ 120$ for at $P A V_{i}=£ 1500$, as shown in Figure $1 \mathrm{~A}$. There are 60,000 auctions within this regime and we focus on this sub-sample to establish our baseline results on the reserve price effects. We refer to this as the Cat-C1 reserve price regime. ${ }^{11}$

\footnotetext{
${ }^{10}$ The design of the website does not therefore differ radically from other online auction formats for vehicles in both the UK and US. Given that the vehicles are supplied by a single insurance firm, there is no notion of the seller's reputation in this setting, and bidders do not operate on both sides of the online market.

${ }^{11}$ This raises three issues: why does the auctioneer find it optimal to have a discontinuity in $R_{i}$, why is it a discontinuous function of $P A V_{i}$, and why does it vary over time? On the first issue, auction theory usually predicts that reserve prices are increasing in the seller's valuation and depend on the distribution of bidder valuations. Calculating the optimal reserve price for every car is potentially costly as it requires the seller to calculate the precise degree of damage and evaluate the distribution of bidder evaluations. By definition, the benefits of such
} 
Columns 2 and 3 detail the other reserve price regimes for Cat-C cars (Cat-C2 and Cat-C3 regimes). In Cat-C2 $R_{i}$ discontinuously jumps at $P A V_{i}=£ 1500$, but the magnitude of the jump differs from that in Cat-C1. A comparison of results from Cat-C1 and Cat-C2 regimes also helps shed light on how reserve price effects vary with the level of the reserve price to begin with. Moreover, in Cat-C2 the reserve price is almost at its lowest feasible level $\left(R_{i}=£ 5\right.$ if $\left.P A V_{i}<£ 1500\right)$ and so this sheds light on whether it might be optimal for the auctioneer to set a zero reserve in this setting, as would be predicted in some parts of the parameter space in models with endogenous bidder entry [Levin and Smith 1994, Bulow and Klemperer 1996].

Finally, Column 3 shows that in Cat-C3 there is no discontinuity in reserve prices at $P A V_{i}=$ $£ 1500$. In this regime $R_{i}=.08 \times P A V_{i}$ for all $P A V_{i}$. We use this regime to provide a falsification check that auction outcomes do not naturally change around $P A V_{i}=£ 1500$ even in the absence of a discontinuity in $R_{i}$.

Columns 4 and 5 show there are two regimes for Cat-B vehicles. In the more recent regime, Cat-B1, $R_{i}$ jumps down from $£ 40$ to $£ 5$ at $P A V_{i}=£ 1500$. We can use this regime to test whether the effects of reserve prices on auction outcomes are of opposite sign to those documented in the baseline regime Cat-C1. Column 5 shows that in the Cat-B2 regime, $R_{i}=£ 5$ for all $P A V_{i}$. This can again be used as a falsification check that auction outcomes do not naturally jump at $P A V_{i}=£ 1500$ for Cat-B vehicles. The final column shows that for Cat-D vehicles, over the entire period, $R_{i}=.1 \times P A V_{i}$ for all $P A V_{i}$ so this regime is used as a further falsification check on auction outcomes at $P A V_{i}=£ 1500$.

Table 2 also presents information for each regime on the percentage of auctions that have $P A V_{i}<£ 1500$ and so lie to one side of any discontinuity in reserve prices. Across Cat-C and Cat-B regimes there is a fairly even split of vehicles either side of the cut-off. As expected a far smaller share of Cat-D vehicles have $P A V_{i}<£ 1500$.

The discussion so far relates to how reserve prices are set in the first time vehicle auctions that we focus on. As shown below, the vast majority of vehicles are sold at first auction. For those that are not, they usually come up for re-auction with the same auctioneer within a week. We observe such re-auctions in our data because each vehicle has a unique identifier that allows us to trace whether it has been auctioned multiple times. The default reserve price for re-auctioned vehicles is $£ 5$ for all salvage categories. ${ }^{12}$

calculations are lower for low-value cars. In the face of such costs, the observed reserve price policy might be a good rule-of-thumb approximation to an optimal reserve policy. In terms of expected revenues, we later document that the reserve price is set at its locally optimal level. On the second issue, we note that $P A V_{i}$ is correlated with winning amounts, and that the ratio of winning amounts to $P A V_{i}$ is less than 0.2 in all vehicle categories. Using a reserve price rule based on the ex ante $P A V_{i}$ is relatively costless for the seller, rather than having to form an independent assessment of any potential damage to the vehicle and bidders' behavior. Finally, the use of reserve price rules that vary over time or induce quasi-experimental variation allows the auctioneer to receive feedback on and learn what might be the optimal reserve price policy.

${ }^{12}$ The marginal cost of holding onto a vehicle is approximately zero for the auctioneer. This cost is borne by the salvage yard where the vehicle is physically located. However, the reserve price in re-auctions is set at its lowest possible value because the auctioneer faces competitive pressure to ensure the salvage yards it works with do not 


\subsection{Vehicle Characteristics by Reserve Price Regime}

Table A1 presents descriptives on vehicles by reserve price regime. $P A V_{i}$ is highest for Cat-D vehicles as expected although there is not much difference in $P A V_{i}$ between Cat-B and Cat-C vehicles. This suggests the extent of damage incurred in the accident is not much correlated to the ex ante value of the vehicle. Table A1 also highlights the detailed list of vehicle characteristics available. These fall into three types. First, we observe a rich set of standard vehicle features such as mileage, transmission etc. Second, we code information relating to the damage the vehicle has suffered. For example we code the number of words in the auction data base that describes the vehicle damage. The third class of characteristic are the make and model of the vehicle - the auctions cover 49 vehicle makes (Audi, BMW, Ford etc.) and around 1200 specific vehicle models, where for example, BMW 316 and BMW 318 are considered to be two different models etc.

\subsection{Auction Outcomes by Reserve Price Regime}

Table 3 provides descriptive evidence on auction outcomes by reserve price regime. Panel A shows those outcomes that have been focused on in the literature. As expected, winning bids are highest for Cat-D vehicles, followed by Cat-C and Cat-B vehicles. Relative to previous studies using online auctions data, the objects considered in our setting are high stakes items. Even in the lowest value Cat-B class, the average winning bid is $£ 229$ in regime Cat-B1 and $£ 183$ in regime Cat-B2. Moreover, we note that winning bids are typically well above the reserve prices in each category. The fact that reserve prices are not binding in this sense ensures that any discontinuities in reserve prices do not mechanically lead to similar discontinuities in winning bids. ${ }^{13}$

The number of entrants varies across categories. Cat-D auctions attract an average of 6.9 bidders, while for the most recent Cat-C regime, Cat-C1, on average 4.5 bidders enter. For the lower valuation Cat-B auctions, less than 4 bidders enter. Across regimes, the vast majority of auctions attract more than one bidder. Finally, we note that less than $4 \%$ of vehicles remain unsold, except in the older Cat-C3 regime when nearly a quarter of vehicles remained unsold. Most vehicles that are unsold come up for re-auction with the same auctioneer, and usually within a week of the original auction. The vast majority of these are then sold at second auction.

Panel B presents descriptive evidence on bidder characteristics and behavior within the auction, by $\mathrm{RD}$ regime. Around two thirds of auction participants have won at least once. For example of the 4862 bidders that have entered at least one Cat-C1 auction, 3156 have won at least once. This ratio of winners to bidders is almost the same in Cat-C1 and Cat-D auctions, and is higher in Cat-B auctions. Across regimes, auction winners have win rates around 4-6\% higher than the

bear significant costs from unsold vehicles. In this paper we focus predominantly on first time auctions and leave a detailed analysis of the dynamic effects across auctions for future research.

${ }^{13}$ The winning amount is, on average, between 2.7 times the reserve price in Cat-C1, Cat-C3 and Cat-D1 auctions, and over 35 times the reserve price in both Cat-B regimes. 
average bidder. Using information on self-reported bidder types, we note that private buyers are far more likely to enter Cat-D auctions, which recall comprise vehicles that require minor or no repairs to return to their original condition. In Cat-B and Cat-C auctions, the vast majority of bidders are professionals.

Panel C presents descriptive evidence from web viewing data that is available for the most recent regimes. There are clearly a number of possible ways to use this information to define potential bidders. At one extreme one could think of search and other entry costs as being zero and so any of the thousands of bidder registered with the auctioneer on auction day are potential bidders. Alternatively, entry might be endogenously determined by the object's characteristics as well as entry costs. The web viewing data reveals that although there are a very large number of bidders that view an auction web page at least once, the number of potential bidders might be better approximated by the number of bidders that then choose to view the auction website a small number of times. In doing so, such bidders acquire more detailed information on the history of bids placed in the auction, but no information on the identity of bidders is revealed.

In Cat-C1 auctions, defining potential bidders as those that view the auction web page at least five times, implies that there are on average 6.64 potential bidders, which is around $50 \%$ more than the average number of actual bidders (4.49). For Cat-D vehicles using the same definition of a potential bidder as someone that have viewed the auction web page at least five times, we find there to be 10.2 potential bidders, which implies an almost identical ratio of potential to actual bidders as in Cat- $\mathrm{C}$ auctions. In contrast, for lower value Cat-B vehicles, we see that very few bidders view the auction website five times. Indeed, there are fewer individuals that do this than actually bid in such auctions. This suggests that for low valued vehicles that are predominantly bought for scrap, bidders need to view the auction web page only once or twice before deciding whether to enter. ${ }^{14}$

\subsection{RD Design}

To identify the causal impact of reserve prices on any given auction outcome, such as the winning bid, we cannot simply compare winning bids in auctions with different reserve prices. As the theory of optimal reserve price setting makes precise, sellers choose reserve prices based on their own valuations and based on the distribution of bidder valuations. Both are likely to be correlated with potentially unobserved vehicle characteristics. ${ }^{15}$ To measure the causal effect of reserve prices

\footnotetext{
${ }^{14}$ These ratios of potential to actual bidders for Cat-C and Cat-D are of similar magnitude to those implied by the structural estimates in Bajari and Hortacsu [2003].

${ }^{15}$ Reserve prices are a function of $P A V$ which is only imperfectly known to bidders. Our primary analysis focuses on the $90 \%$ of auctioned vehicles that originate from one large insurer. In a separate analysis of the remaining vehicles auctioned by the same auctioneer, vehicles supplied by private sellers, we also find reserve prices to be significantly correlated to a series of vehicle characteristics such as mileage, whether the vehicle uses petrol as opposed to diesel, whether the keys are available and reported damage. Such vehicle characteristics have also been found to be correlated to bidder entry and winning amounts in other similar settings [Roberts 2013].
} 
on winning bids we exploit the previously documented discontinuities in the relationship between the pre-accident value $\left(P A V_{i}\right)$ and the reserve price $\left(R_{i}\right)$. The RD design identifies the impact of a binary treatment $W_{i}$ on the observed outcome in auction $i, Y_{i}$. In our baseline regime Cat-C1 described in Column 1 of Table 2, the treatment variable $W_{i}$ relates to whether the reserve price is set at a low value of $R_{i}=£ 40$ (so $W_{i}=0$ ), or whether it is set at a high value of $R_{i}=.08 \times P A V_{i}$ (so $\left.W_{i}=1\right)$. Hence the observed outcome can be written as,

$$
Y_{i}=\left(1-W_{i}\right) Y_{i}(0)+W_{i} Y_{i}(1)=\left\{\begin{array}{l}
Y_{i}(0) \text { if } W_{i}=0 \\
Y_{i}(1) \text { if } W_{i}=1
\end{array}\right.
$$

Treatment assignment depends only on whether $P A V_{i}$, is above or below a fixed cut-off, $P A V_{c}=$ $£ 1500$, so $W_{i}=1\left(P A V_{i} \geq P A V_{c}\right)$ so we have a sharp regression discontinuity design (SRD) because $W_{i}$ is a completely deterministic function of $P A V_{i}$ [Hahn et al. 2001]. The identified parameter, denoted $\tau_{S R D}$, is the average causal effect of the treatment at the discontinuity,

$$
\begin{aligned}
\tau_{S R D} & =E\left[Y_{i}(1)-Y_{i}(0) \mid P A V=P A V_{c}\right] \\
& =\lim _{P A V \downarrow P A V_{c}} E\left[Y \mid P A V=P A V_{c}\right]-\lim _{P A V \uparrow P A V_{c}} E\left[Y \mid P A V=P A V_{c}\right]
\end{aligned}
$$

We estimate this using non-parametric local linear regression methods as these have desirable properties with regards to speeds of convergence and bias [Fan and Gijbels 1996]. The kernel bandwidth is chosen to give positive weight to at least 30 observations on each side of the discontinuity when estimating (3), and we use triangular kernels. In the Appendix we show the robustness of our results to alternative choices of bandwidth and kernel.

\section{Bidders' Behavior}

We first estimate the causal impact of public reserve prices on outcomes related to bidders' behavior. We focus on outcomes emphasized in the theoretical literature: winning bids conditional on sale, the number of actual bidders, and the probability the object is sold. As summarized in Table 1, theory suggests reserve price impacts on these margins depend on three factors: (i) whether bidders have private or common valuations of the auctioned object; (ii) whether bidder entry is exogenous or endogenously determined; (iii) whether the reserve price signals the auctioneer's private information on the true value of the auctioned object. Theory provides ambiguous predictions on the impact of reserve prices on these margins. Hence our first contribution is to

provide credible estimates of the causal impact of reserve prices on these margins and to begin to shed light on the most parsimonious class of models that best characterize this complex auction environment. 


\subsection{Descriptive Evidence on Outcomes Around the Discontinuity}

We provide preliminary evidence of the impact of discontinuities in $R_{i}$ on these auction outcomes from Cat-C1 vehicle auctions, the most frequently observed RD regime in our sample. Given that treatment assignment is determined by whether $P A V_{i}$ lies above or below the discontinuity at $£ 1500$, we define the assignment variable as $\left(P A V_{i}-1500\right)$. We then plot estimates of the average value of the outcome $Y_{i}$ in bins either side of zero for the assignment variable. We use bin widths of 50 and plot average outcomes, and the associated $95 \%$ confidence interval, over the range \pm 500 of the assignment variable, against the mid-point of each bin.

In Figure 1B we see evidence of a jump in the average winning bid in the bins either side of the discontinuity. There is no evidence of comparable jumps in winning bids between any other pair of adjacent bins for the assignment variable. As described in Table 2, the magnitude of the jump in the reserve price is $£ 80$ as $R_{i}$ jumps from $£ 40$ for $P A V_{i}<£ 1500$, to $£ 120$ at the cut-off when $P A V_{i}=£ 1500$. Figure $1 \mathrm{~B}$ suggests the magnitude of the jump in winning bid at this cut-off is around $£ 40$. Hence the winning bid responds less than one-for-one to changes in $R_{i}$. This is to be expected given the evidence in Table 3 that winning bids tend to be far higher than the reserve price to begin with. Figure $1 \mathrm{C}$ provides descriptive evidence on how the number of bidders varies in bins either side of the assignment variable. We see a significant fall in the number of bidders at the reserve price discontinuity. ${ }^{16}$

Moreover, if in Figure 1C we focus on assignment values away from the cut-off, then the descriptive evidence suggests there to be an implied positive correlation between $R_{i}$ and the number of bidders. This is in sharp contrast to the implied negative causal impact of $R_{i}$ on the number of bidders as evaluated precisely at the cut-off. In short, the descriptive evidence suggests that absent a credible research to uncover causal reserve price effects, there is the possibility of correlations between reserve price and outcomes such as the number of bidders being of the opposite sign to the true relationship. ${ }^{17}$

In the Appendix we describe a series of checks on the credibility of the RD design: (i) whether discontinuities in auction outcomes at the cut-off remain conditional on observable vehicle characteristics; (ii) whether the assignment variable is smooth around the discontinuity or appears to have been manipulated by the seller; (iii) whether there is endogenous sorting of bidders either side of the cut-off.

\footnotetext{
${ }^{16}$ As further assurance that the relationship between the winning amount and reserve price is not purely mechanical, we note that there is also a jump in winning bids at the discontinuity for auctions with at least two bidders. Indeed the magnitude of the jump in winning bids is slightly larger than in Figure 1B.

${ }^{17}$ This has implications for some psychological models of auctions. For example, models of auction fever suggest sellers set reserve prices below their true valuation to induce competition in ascending or open bid auctions. The most common prediction tested is that winning bids are increasing in the number of bidders, as surveyed in Ockenfels et al. [2007]. The descriptive evidence and our RD estimates do not support this as the causal impact of the reserve price on the number of bidders and winning bids is of opposite sign.
} 


\subsection{RD Estimates: Cat-C1 Auctions}

Column 1 of Table 4 presents baseline RD estimates of the impact of reserve prices on winning bids and the number of entrants from Cat-C1 auctions. These estimates are shown in Panels A and $\mathrm{B}$ and imply that increasing the reserve price from $£ 40$ to $£ 120$ has the following impact for vehicles with $P A V_{i}=£ 1500$ : (i) increases the winning bid by $£ 33.6$; (ii) decreases the number of bidders by 1.33. Both effects are significant at the $1 \%$ significance level and are in line with the descriptive evidence presented in Figures 1B and 1C. To more easily compare these estimates to those derived from the other $\mathrm{RD}$ regimes, Column 1 shows the implied marginal effect of a $£ 1$ increase in the reserve price on each outcome, and the associated $95 \%$ confidence interval for the implied marginal effect. The implied effect of a $£ 1$ increase in the reserve price is to increase the winning bid by $£ .42$, and to decrease the number of bidders by .02 .

Figure 2 shows the non-parametric RD estimates over a wide range of the assignment variable for both auction outcomes. These confirm the jump in each outcome variable at the reserve price discontinuity. Both figures confirm that when auctions with at least two entrants are considered and so the mechanical effect of reserve prices on winning bids is entirely eliminated, there remain large effects on winning amounts and the number of auction entrants.

Following the discussion in Imbens and Lemieux [2008] on RD designs, Appendix Table A3 presents robustness checks on these baseline estimates relating to: (i) limiting the sample to auctions in which at least two bidders enter; (ii) narrowing the range of the assignment variable, $\left(P A V_{i}-1500\right)$, to lie between the median above and below the actual cut-off value; (iii) placebo cutoffs; (iv) alternative bandwidths, kernels, and standard error calculations.

The third outcome auction theory provides relatively robust predictions on is the effect of reserve prices on the likelihood the object remains unsold. These RD estimates are shown in Panel C of Column 1 in Table 4. In the baseline regime Cat-C1, higher reserve prices significantly increase the likelihood the item remains unsold. The marginal effect is .003, relative to a baseline probability of the vehicle being unsold of $4.2 \%$. Given the possibility that expected revenues are lower at second auction, this channel represents a first order cost of higher reserve prices.

These results are in line with the earlier evidence from experiments on reserve price effects in online auctions [Reiley 2006, Brown and Morgan 2009, Ostrovsky and Schwarz 2009], although only the first of these presents evidence on reserve price effects of the item being unsold. As shown in the next Section, in the absence of structural modelling, this outcome needs to be estimated in order to make claims on the (local) optimality of reserve prices that are set by the auctioneer.

Our findings so far have two implications for how this setting maps to the predictions of auction theory, as summarized in Table 1. First, the result that the reserve price effects on the number of bidders and the winning bid are of opposite sign rules out a benchmark second-price auction model of bidders holding IPV with exogenous entry and bidding their true valuation. This is because in that model the winning bid is independent of the reserve price if the reserve price is not binding. 
Of course, as noted by Bajari and Hortacsu [2003], the fact that the reserve price effects are of opposite sign for the number of bidders and winning bids remains consistent with richer models that allow for affiliated or common values. ${ }^{18}$ Second, the results so far rule out that if bidder entry is endogenous, higher reserve prices curtail entry to such an extent so as to decrease winning bids conditional on sale. Hence, it is unlikely that the auctioneer would find it optimal to set no reserve, a result confirmed later when we study the optimality of the seller's behavior.

\subsection{RD Estimates: Other Reserve Price Regimes}

The remaining columns of Table 4 explore the consistency of these estimates across the full range of discontinuity regimes we observe. All jumps in reserve price occur at $P A V_{i}=£ 1500$, although the magnitude and direction of these jumps vary across the regimes.

To begin with, Columns 2 and 3 focus on the other Cat-C regimes. In regime Cat-C2 the jump in reserve prices is from $£ 5$ for $P A V_{i}<£ 1500$, to $£ 120$ at the cut-off when $P A V_{i}=£ 1500$. Despite the jump in $R_{i}$ being of larger magnitude, we find the implied marginal effects of $\Delta R_{i}=£ 1$ to be very similar to those in the baseline regime Cat-C1. More precisely, the marginal effect on the winning bid is $£ .35$ and this is not significantly different to the marginal effect of $£ .42$ found in Cat-C1. Moreover, the implied marginal effect on the number of bidders of .02 is nearly identical to that found in regime Cat-C1. Finally, the reserve price impact on the likelihood the vehicle remains unsold is also of comparable magnitude across regimes Cat-C1 and Cat-C2.

Recall that in regime Cat-C2, to the left of the discontinuity the reserve price is set almost at its lowest possible level: $R_{i}=£ 5$ for $P A V_{i}<£ 1500$. Hence the results strongly suggest that in this environment we are not in a part of the parameter space where it is optimal for the auctioneer to set a zero reserve price [Levin and Smith 1994, Bulow and Klemperer 1996]. We later explicitly examine whether the auctioneer sets her reserve price at the locally optimal level.

Regime Cat-C3 provides a falsification check on these results because during that time period there is no discontinuity in reserve prices for Category-C vehicles at $P A V_{i}=£ 1500$ or at any other $P A V_{i}$. Reassuringly we observe there to be no significant change in any of the three outcomes in Cat-C3, suggesting there are no natural jumps in auction outcomes around $P A V_{i}=1500$.

\footnotetext{
${ }^{18}$ While the results do not allow us to infer whether bidder valuations are best characterized as being private, affiliated or common, we note that bidder valuations might actually differ depending on the type of vehicle category considered. Cat-C vehicles are bought for the value of their spare parts and so it seems likely that bidders' valuations contain a significant private value component. In contrast, Cat-B vehicles are predominantly purchased for their scrap metal value. There is a common market price for scrap but information about the overall market quality might be dispersed amongst bidders. Hence the argument for bidders having pure common values is perhaps more compelling than for Cat-C vehicles. A large literature exists on empirical tests to distinguish private and common values, as summarized in Hendricks and Porter [2007]. We have explored some of these tests, although no single test is necessarily conclusive because inevitably each tests a joint hypothesis on both the nature of bidder valuations and some other aspect of the auction environment, such as exogenous bidder entry. With this caveat in mind we note that, following the discussion of the test based on the winners' curse in Milgrom and Weber [1982] and Bajari and Hortacsu [2003], we find that for Cat-C1 vehicles, the average bid of a given bidder is increasing in the number of bidders in line with both an affiliated private values and common values environment [Pinske and Tan 2005].
} 
Column 4 repeats the analysis for regime Cat-B1 where the reserve price jumps down from $£ 40$ for $P A V_{i}<£ 1500$, to $£ 5$ at the $P A V_{i}=£ 1500$ cut-off. As the reserve price falls there is no significant effect on the winning bid, but the number of bidders significantly increases. The implied marginal effect is far smaller than in the Cat-C1 or Cat-C2 regimes. Column 5 uses the Cat-B2 regime in which there is no jump in the reserve price at $P A V_{i}=£ 1500$ as a falsification check. We find no evidence of there being a natural jump in auction outcomes at this $P A V_{i}$ for the low value vehicles in Category-B. Finally, Column 6 repeats the analysis for Category-D vehicles for which there is never a jump in reserve prices over the entire study period. Reassuringly we also find that for high value vehicles there is no natural jump in auction outcomes at $P A V_{i}=1500$.

Comparing our results to estimates of reserve price effects based on field experiments, we find that consistent with that body of evidence: (i) expected seller revenues rise conditional on sale, as in Reiley [2006], Brown and Morgan [2009], and Ostrovsky and Schwarz [2009]; (ii) the number of bidders falls, as estimated in Reiley [2006] and Ostrovsky and Schwarz [2009]; (iii) the likelihood the object is sold falls, as also reported in Reiley [2006].

Despite this reassuring similarity of findings, there are some more subtle differences in findings that are worth highlighting. For example, comparing the RD estimates from Cat-C1 and Cat-C2 regimes, to those in the Cat-B1 regime, the evidence implies outcomes are more sensitive to reserve prices in: (i) auctions with more actual entrants; (ii) auctions for objects that have higher ex ante valuations. This first result is counter to the evidence from field experiments presented in Reiley [2006] from online auctions for collectible trading cards, and those in Ostrovsky and Schwarz [2009] from online auctions for advertisements. Both those papers find reserve price effects to be larger in auctions in which a smaller number of bidders enter.

Of course there are potentially many differences across these auction environments that might drive these differences - the auction format in Reiley [2006] is a first price auction, and the setting in Ostrovsky and Schwarz [2009] is best modelled as a generalized second price auction environment in which multi-unit items are sold. Also, the nature of bidders valuations - be they private, affiliated, common, or some combination, might also differ across these objects.

Finally, we note that a limitation of RD designs is that they effectively identify a weighted average treatment effect of $W_{i}$, where the weight is proportional to the ex ante likelihood that an individual realization of $P A V_{i}$ will be close to the cut-off [Lee and Lemieux 2010]. In our setting there is no particular economic significance to basing our RD estimates around the $P A V_{i}=£ 1500$ cut-off. In the Appendix we address this concern and therefore bolster the external validity of our results, using two strategies: (i) we exploit the variation over time within a vehicle category to present difference-in-difference estimates of the impact of changes in reserve price on auction outcomes; (ii) we exploit data from Category-C auctions that have taken place between December 2008 and June 2010, in which all aspects of the auction environments are unchanged except that the discontinuity between $P A V_{i}$ and $R_{i}$ occurs at $P A V_{i}=£ 2000$. 


\section{Seller's Behavior}

\subsection{Optimality of Reserve Prices}

We now study the auctioneer's revenue maximization problem. To see how the documented RD estimates map to the auctioneer's expected revenue we use $\pi$ to denote the auctioneer's revenue from a vehicle's auction, and define a dummy variable $S$, set equal to one if the vehicle is sold in its first auction, and zero otherwise. $\operatorname{Pr}\left[S=1 \mid P A V=P A V_{c}\right]$ denotes the probability the vehicle is sold at first auction, $E\left[\pi \mid P A V=P A V_{c}, S=1\right]$ denotes the expected revenue conditional on the object being sold at first auction and $E\left[\pi \mid P A V=P A V_{c}, S=0\right]$ denotes the expected revenue from re-auctioning in second or potentially higher auctions. Hence the auctioneer's ex ante expected revenue is,

$$
\begin{aligned}
E\left[\pi \mid P A V=P A V_{c}\right]= & E\left[\pi \mid P A V=P A V_{c}, S=1\right] \operatorname{Pr}\left[S=1 \mid P A V=P A V_{c}\right] \\
& +E\left[\pi \mid P A V=P A V_{c}, S=0\right] \operatorname{Pr}\left[S=0 \mid P A V=P A V_{c}\right] \\
= & E\left[\pi \mid P A V=P A V_{c}, S=1\right] \\
& +\left\{\begin{array}{c}
E\left[\pi \mid P A V=P A V_{c}, S=0\right] \\
-E\left[\pi \mid P A V=P A V_{c}, S=1\right]
\end{array}\right\} \operatorname{Pr}\left[S=0 \mid P A V=P A V_{c}\right] .
\end{aligned}
$$

where all components are evaluated for vehicles at the regression discontinuity, namely vehicles for which $P A V_{i}=P A V_{c}=£ 1500$. Two points are of note. First, as shown in Table 3, the vast majority of vehicles are sold at first auction. Those that are re-auctioned are usually sold at the second auction. For expositional ease, we therefore refer to outcomes when $S=0$ as what occurs if the vehicle comes up for second auction. Second, the marginal cost of holding onto an unsold vehicle is approximately zero for the auctioneer. This cost is borne by the salvage yard where the vehicle is physically located. Hence in this setting, most costs are fixed and so changes in revenue translate almost one-for-one into changes in profit. The marginal impact of $R_{i}$ on expected revenue (or profit), as evaluated at the discontinuity where $P A V_{i}=P A V_{c}=£ 1500$, can be decomposed into three terms,

$$
\begin{aligned}
& \frac{\Delta E\left[\pi \mid P A V=P A V_{c}\right]}{\Delta R_{i}} \\
= & \frac{\Delta E\left[\pi \mid P A V=P A V_{c}, S=1\right]}{\Delta R_{i}} \\
& +\left\{\begin{array}{c}
E\left[\pi \mid P A V=P A V_{c}, S=0\right] \\
-E\left[\pi \mid P A V=P A V_{c}, S=1\right]
\end{array}\right\} \frac{\Delta \operatorname{Pr}\left[S=0 \mid P A V=P A V_{c}\right]}{\Delta R_{i}} \\
& +\left\{\begin{array}{c}
\frac{\Delta E\left[\pi \mid P A V=P A V_{c}, S=0\right]}{\Delta R_{i}} \\
-\frac{\Delta E\left[\pi \mid P A V=P A V_{c}, S=1\right]}{\Delta R_{i}}
\end{array}\right\} \operatorname{Pr}\left[S=0 \mid P A V=P A V_{c}\right]
\end{aligned}
$$


The first term is the impact of the reserve price on the winning amounts in the auction conditional on the item being sold. This is identified from the documented RD estimate in Table $4 .{ }^{19}$

The second term comprises two components: the first is just the average difference in winning amounts between the first time auction, and expected revenue conditional on the item remaining unsold at first auction. This average value can be simply observed in the data. The second component is the impact of the reserve price on the likelihood the item remains unsold at first auction, which is again identified from the RD estimate in Table 4.

The final term comprises two components. The component outside the parentheses is the probability the item is unsold at first auction and can be observed from the data. The component in parentheses corresponds to the differential impact the reserve in the first auction, $R_{i}$, has on winning amounts in first and second auctions. The effect on the first time auction $\frac{\Delta E\left[\pi \mid P A V=P A V_{c}, S=1\right]}{\Delta R_{i}}$ is the RD estimate described above. The effect on the expected revenue in the second time auction $\frac{\triangle E\left[\pi \mid P A V=P A V_{c}, S=0\right]}{\Delta R_{i}}$ is the one component of (5) that we need to estimate using non-experimental methods. To do so requires using data from second time auctions, which are identified in our data. In the Appendix we describe how we use OLS to estimate the correlation between the reserve price in the first-time auction and the winning bid in the second time auction. ${ }^{20}$

\subsection{Results}

Table 5 shows each component of (5) for Cat-C1 vehicles. The components in Columns 1 to 3 are descriptives from the data. The components in Columns 4 and 6 are derived from the previously documented RD estimates in this regime. The component in Column 5 is based on the non-experimental estimates from second time auctions described above and in the Appendix. As the RD estimates exploit auctions in which $P A V_{i}=P A V_{c}=£ 1500$, all the descriptives are constructed for such auctions.

The last column then substitutes all of these components into (5) to evaluate the marginal effect of reserve prices on the auctioneer's expected revenue. We find this marginal effect to be -.030 so that if the auctioneer were to raise her reserve price by $£ 1$, then for vehicles with $P A V_{i}=£ 1500$ her expected revenue (and profit) would decrease by $£ .03$. To reiterate, this estimate takes account of reserve price effects on winning bids in the first time auction, as well as the reserve price effect on the possibility the vehicle remains unsold and outcomes in second auctions.

The next two rows provide upper and lower bounds on this estimated marginal effect. To do so, we note that (5) is a linear combination of: (i) marginal effects estimated from the RD designs, and so these coefficients have a corresponding $95 \%$ confidence interval; (ii) estimated descriptive

\footnotetext{
${ }^{19}$ It should also be noted that we are implicitly assuming that vehicle auctions are independent of each other, and we are measuring the private return to reserve prices to this auctioneer and ignoring any impact this auctioneer's reserve prices might have on other auctioneers in the marketplace. Our approach is therefore very much in line with earlier structural and experimental estimates on whether auctioneer's behave optimally.

${ }^{20}$ Theory does not offer much guidance on the expected sign of this marginal effect. Indeed such dynamic effects within re-auctions are not much studied [McAfee and Vincent 1997].
} 
means, which again have corresponding 95\% confidence intervals. To provide a lower bound on the first order condition we use the appropriate extreme values of the estimate or statistic, taken as the extreme value from the $95 \%$ confidence interval. The linear combination of these extreme values then provide upper and lower bounds on the marginal impact of the reserve price on the auctioneer's ex ante expected revenue. Table 5 then shows the marginal reserve price effect lies between -.162 and .105. As this contains zero we conclude that the auctioneer is setting her reserve prices to be locally optimal. Hence, in line with the earlier RD findings, even if bidder entry is endogenous, it is not the case that we are in that part of the parameter space where the seller finds it optimal to set a reserve price at zero.

It is worth comparing our results on seller's behavior with other strands of the empirical literature. Our results are in contrast to evidence from laboratory settings. For example, Barrymore and Raviv [2009] find that reserve prices decrease the number of bidders, increase revenue conditional on sale, but seller's profits are maximized by setting no reserve because of the negative effect of reserve prices on the likelihood of sale. We don't find such severe effects of reserve prices on entry in our field setting, so that strictly positive reserve prices are found to be locally optimal. ${ }^{21}$ In terms of evidence from field experiments, only Reiley [2006] presents evidence on all the margins required to estimate the equivalent of (5). He reports mixed evidence on auctioneer's behaving optimally. He finds that revenues are locally declining in the reserve price, although this negative effect is not precisely estimated. Finally, estimates based on structurally models have been mixed, with some authors finding reserve prices set too low in o- ine auctions [Paarsch 1997], and others finding auctioneers' setting reserve prices optimally in online settings [Bajari and Hortacsu 2003].

\section{New Evidence on Bidder Composition}

We now move beyond the narrow set of outcomes emphasized by auction theory. We exploit the richness of our data to probe further how reserve prices impact on novel margins of behavior and to shed more light on how best to characterize the auction environment. First, we use data on individual web browsing behavior to determine the impact of reserve prices on the number of potential bidders; those individuals who click on an auction webpage, draw a private signal and decide whether to bid. This margin of impact provides evidence on whether bidder entry is endogenous. Second, exploiting data on bidder histories with the auctioneer dating back to January 2003, we study how bidder characteristics change with reserve prices. This sheds further light on whether bidder entry is endogenous and also on whether bidders valuations are asymmetric.

\footnotetext{
${ }^{21}$ Harrison [1989] provides a critique of the ability of experimental evidence to identify real world payoff functions and therefore be able to extrapolate from lab settings to optimal behavior in field settings.
} 


\subsection{Potential Bidders}

We use web browsing of "web-view" data to explore how reserve prices impact the number of potential bidders. Web-view data is available for the most recent auctions in the Cat-C1 and Cat-D1 regimes. We define the potential number of bidders in an auction as those that view the auction webpage at least five times. The results presented are robust to small changes to this definition. Panel A of Table 6 shows that in Cat-C1 auctions, the number of potential bidders significantly falls with higher reserve prices. Some bidders on the margin of entry choose not to enter as reserve prices rise.

The implied marginal effect however shows that the number of potential bidders is less sensitive to the reserve price than is the number of actual bidders previously documented in Table 4 - the marginal effects of reserve prices on potential and actual bidders are -.003 and -.017 respectively. ${ }^{22}$ This suggests that search behavior, as measured by web browsing histories, is far less sensitive to reserve prices than are actual entry decisions.

We provide two falsification checks on this result. The first exploits the Cat-D1 regime where there is no jump in $R_{i}$. As shown in the final column of Panel $\mathrm{A}$, there is no significant change in the number of potential bidders at $P A V_{i}=£ 1500$. The second check estimates how jumps in the reserve price affect the number of bidders that view the web page once, reported in Panel B. Recall that when potential bidders first view the auction web page, no information is revealed about the reserve price. Hence there ought to be no effect of the reserve price on the number of bidders that view the web page once. Reassuringly, the results in Panel B confirm this is the case.

\subsection{Bidder Characteristics}

We next explore how the average characteristics of entrants in general, and winners in particular, are impacted by reserve prices. We focus on two characteristics: bidder win rates as defined in (1), and the months the bidder has been registered with the auctioneer as a proxy for their bidding experience. There is a significant heterogeneity across bidders in these characteristics. For example, the heterogeneity in bidder win rates documented in Panel $\mathrm{C}$ of Table 3 suggests that, conditional on entry, certain bidders are more likely to win than others; this may result from them having higher average valuations than others. Similarly, it is plausible that more experienced bidders are better informed about objects' true valuations than less experienced bidders. If bidders are asymmetric because they draw private signals from different distributions or because they are asymmetrically informed about the valuation of the objects being auctioned, these two characteristics are good proxies for bidder asymmetry.

Panels $\mathrm{C}$ and $\mathrm{D}$ in Table 6 present the RD estimates on these margins, where we first average

\footnotetext{
${ }^{22}$ Bajari and Hortacsu [2003] present structural estimates that also find a significantly negative effect of public reserves on the number of potential bidders. Although not directly reported, their estimates also seem to imply the number of potential bidders is less sensitive to reserve prices than the actual number of bidders.
} 
each characteristic over all bidders that enter. Column 1 shows that as reserve prices rise in Cat$\mathrm{C} 1$ auctions, the average win rate and bidding experience of bidders that remain in such auctions, significantly increase. Put another way, less experienced bidders and less successful bidders are those that choose not to enter auctions with higher reserve prices, all else equal. ${ }^{23}$

While the implied marginal effects on bidders' characteristics of $\Delta R_{i}=£ 1$ are small as is to be expected, the magnitude of the effect at the jump actually observed, $\Delta R_{i}=£ 80$ in Cat-C1 auctions, is large and economically significant. To see this, note that from Column 1 of Table 3 the standard deviation of win rates among bidders is .082. Hence the RD estimate suggests a considerable effect on win rates. Moving incrementally from one side of the cut-off to the other, all else equal, increases the win rates of those bidders that still choose to enter by $13 \%$ of a standard deviation $(0.11 / 0.82)$.

Two implications follow. First, it ameliorates the econometric concern that more experienced bidders are informed about the discontinuous relationship between $P A V_{i}$ and $R_{i}$. If that were the case we would expect to see a significant bunching of more experienced bidders to the left of the cut-off. The RD estimates suggest the opposite. Second, if bidder characteristics correlate to bidder valuations or information, this result strongly suggests that bidder entry decisions are endogenous in the sense that the valuations of bidders that enter the auction differ markedly from those that could have potentially entered the auction. ${ }^{24}$

The remaining Columns in Panels C and D show that: (i) as with the reserve price estimates on all other margins, the marginal effects are of similar magnitude and significance in Cat-C1 and Cat-C2 regimes; (i) in lower value Cat-B1 auctions, where recall the RD estimate is identified from a jump down in the reserve price at the $P A V_{i}=£ 1500$ cut-off, the implied marginal effect on the win rate of bidders is of the same sign and magnitude as in Cat-C1 auctions, but only borderline significant, while there are no significant reserve price effects on bidders' experience; (iii) the falsification checks based on the Cat-C3, Cat-B2 and Cat-D1 regimes suggest that there is no natural jump in bidder characteristics at the $P A V_{i}=£ 1500$ cut-off in any vehicle category.

Panels $\mathrm{E}$ and $\mathrm{F}$ repeat the analysis focusing on the characteristics of the auction winner. We see that there is a somewhat similar pattern of reserve price effects. In particular: (i) winning bidders have significantly higher win rates in Cat-C1 and Cat-C2; (ii) in Cat-B1 auctions the stronger effect appears to be on the win rate of winners rather than their experience; (iii) the falsification checks in Cat-B2 and Cat-D1 regimes are passed, although there is a significant effect in Cat-C3. However this finding is somewhat inconclusive as the effect is actually of the opposite

\footnotetext{
${ }^{23}$ Similar results are also obtained if we redefine these bidder characteristics as relating to experience and win rates within Category-C auctions for example.

${ }^{24}$ As shown in Figure A1D and discussed further in the Appendix, the raw correlation between the assignment variable $\left(P A V_{i}-1500\right)$ and the average win rate of entrants is of opposite sign to the RD estimates - we generally observe auctions with higher reserves being correlated to lower win rates among bidders. This again highlights another margin in which in the absence of a credible research design that accounts for the endogeneity of reserve prices, can lead to estimates of reserve price effects that are of the wrong sign.
} 
sign to that in Cat-C1 and Cat-C2.

Finally, comparing the reserve price effects on winners to those on the average entrant in regime Cat-C1, we see that the implied marginal effects on both winning bidder characteristics are significantly smaller than for the average bidder. This suggests, as is intuitive, that winning bidders are not the marginal entrant into the auction as reserve prices rise, all else equal. This is strongly suggestive of bidders being asymmetric, a feature that is not much studied in the theoretical literature.

Taken together, the results on margins of behavior studied in the Section are informative for the development of future theory. Existing auction models typically remain silent on how bidder characteristics might be affected by reserve prices, how such characteristics relate to bidder valuations or information, and the impact of reserve prices in environments in which bidders hold asymmetric valuations or are asymmetrically informed.

\section{Discussion}

This paper contributes to the empirical literature on auctions by presenting evidence from 260,000 online auctions of second-hand cars to identify the impact of public reserve prices on auction outcomes. To establish causality, we present evidence from multiple regression discontinuity (RD) research designs. We find an increase in reserve price: (i) decreases the number of actual bidders; (ii) decreases the likelihood the object is sold; (iii) increases expected revenue conditional on the object being sold. Bringing together these estimates to calibrate the overall impact of reserve prices on the auctioneer's expected revenue, we find that the reserve price policy followed by the auctioneer is locally optimal in that a small change in reserve price would not significantly change the seller's expected revenue or profit. At a final stage of analysis, we have presented novel evidence on reserve price impacts on margins that suggest bidder entry is endogenous and bidder valuations are asymmetric in this setting.

The richness of our data opens up a broad research agenda for future work. First, the data can be used to better understand dynamic effects across auctions in first and second time auctions for the same vehicle. This has entered as one component of the calibration of the auctioneer's first order condition for expected revenue maximization shown in Table 5. One dynamic feature that is revealed in this calibration exercise is that if the auctioneer could somehow reduce the marginal impact of the reserve price on the likelihood the object remains unsold (namely set the component in Column 3 to zero), then the main channel through which the auctioneer incurs costs from setting higher reserves, would be shut down. With no adverse effect on the likelihood the object remains unsold, the auctioneer might then find it optimal to raise reserve prices all else equal. It is of interest to study such dynamic effects because: (i) such effects potentially exist whenever positive reserve prices are set; (ii) re-auction reserve prices are found to be a qualitatively 
important determinant of objects being sold in first term auctions and hence on the auctioneer's expected revenue.

A second direction to explore in future research is to better account for bidders' behavior when searching over auctions. By exploiting data on web browsing histories, we will be able to contribute to the nascent literature on search and transactions in online environments [Hortacsu et al. 2012]. Again, preliminary data analysis suggests that the prominence with which auctions are displayed to potential bidders when they first log onto the website has significant effects on the likelihood they enter and their subsequent bidding behavior. This opens up the possibility of jointly structurally estimating a model of online search and behavior conditional on entry. This helps open up new avenues in research related to how much studied auction features such as reserve prices, interact more broadly with the design of online environments.

\section{A Appendix}

\section{A.1 Credibility Checks on the RD Design}

We divide these checks into three types: (i) whether discontinuities in auction outcomes at the cutoff remain conditional on observables; (ii) whether the assignment variable is smooth around the discontinuity or appears to have been manipulated by the seller; (iii) whether there is differential endogenous sorting of bidders either side of the cut-off.

On the first check, to see if the evidence of discontinuities in outcomes remains once we take account of information on covariates $Z_{i}$, we follow Lee and Lemieux [2010] and proceed in two steps. We first form predictions of auction outcomes based on regression analysis. We then construct the residuals from the regression model, and then plot the average residual in bin widths of 50 over the range \pm 500 of the assignment variable against the mid-point of each bin. We do this for the baseline Cat-C1 regime.

Denote the winning bid in auction $j$ for a vehicle of model $m$ in time period $t$ as $w_{j m t}$. This corresponds to the maximum of the second highest bid placed in the auction and the reserve price. The vehicle has observable characteristics $Z_{j}$, including its model $m$. A model refers to a specific vehicle manufacturer and vehicle type, so that for example a BMW 316 and BMW 318 are distinct models. As shown at the foot of Table A1, there are 980 unique vehicle models in Cat-C1 auctions. Time $t$ is measured as months since January 2003. We then estimate the correlates of the log of winning bids using the following panel data model,

$$
\log w_{j m t}=\alpha_{m}+\beta_{t}+\Pi \mathbf{Z}+u_{j m t}
$$

where $\alpha_{m}$ and $\beta_{t}$ are model and time fixed effects respectively, $\mathbf{Z}$ is the matrix of other observable characteristics of the vehicle including the $\log$ of the pre-accident value, log of the indicated 
mileage, dummies for whether the vehicle uses petrol rather than diesel fuel, whether it is manual transmission, whether the keys are available, whether a service history is available, whether the V5 logbook is available, whether it is an EU import, the log of the number of words describing damage to the vehicle recorded on the auction web page, a series of dummies for each year of manufacture, and dummies for the salvage year at which the vehicle is located. Robust standard errors are calculated. Importantly we do not control for the reserve price in (6). ${ }^{25}$

We also predict the number of bidders expected to enter the auction using a fixed effects Poisson model [Hausman et al. 1984], and we use a linear probability model to estimate the probability of the item being unsold at first auction. In both specifications we control for the same set of covariates as described above.

Table A2 reports the results. Column 1 shows that this rich of covariates explains $82 \%$ of the variation in the log of the winning bid. Moreover the estimated marginal effects on some of the covariates can also be validated. For example, the marginal effect of having the keys available, evaluated at the mean, corresponds to an increase in the winning bid $w_{j m t}$ of $£ 26.5$ for Cat-C1 vehicles. This corresponds closely to the true cost of acquiring keys for such category of vehicle. Finally, as is intuitive we find that many of the covariates have the same signed marginal effect on the winning bid and the number of entrants, and have the opposite signed marginal effects on the probability of the vehicle remaining unsold at first auction. ${ }^{26}$

For winning bids we take the residuals from (6). Figure A1A shows the average residual, and its associated 95\% confidence interval, in bins of width 50 either side of zero for the assignment variable over the range \pm 500 . As with the unconditional descriptive evidence in Figure $1 \mathrm{~B}$, this shows a clear discontinuity in the residuals precisely at the discontinuity, with no correspondingly similar jumps in average residuals between other adjacent bins. Given that we do not control for $R_{i}$ in (6) this result is highly suggestive of there being an reserve price effect on winning bids conditional on the rich set of vehicle characteristics embodied in $\mathbf{Z}$ and the model fixed effects $\alpha_{m}$.

Figure A1B shows analogous results based on the fixed effects Poisson regression for the number of bidders. For expositional ease we show how the predicted number of bidders varies with the assignment variable. As with the unconditional descriptive evidence in Figure 1C, the data clearly shows, conditional on covariates, there exists a substantial jump in the predicted number of bidders at the cut-off.

The second set of evidence we provide on the credibility of the $\mathrm{RD}$ design relates to manipulation of the assignment variable. The econometric concern is whether vehicle $P A V$ s are manipulated to lie on one side of the cut-off or the other. To check for this, Figure A1C shows

\footnotetext{
${ }^{25}$ In the UK, the V5 Logbook is required to transfer the legal ownership of a vehicle from seller to buyer. The logbook is also required to then register the vehicle in the buyer's name.

${ }^{26}$ We also estimated a specification analogous to (6) using a random effects Tobit model to take account of the dependent variable being censored at the reserve price, where the random effect was the vehicle model. This led to the majority of coefficients having the same sign and significance as those reported.
} 
the kernel density of the assignment variable, $\left(P A V_{i}-1500\right)$. Two points are of note. ${ }^{27}$

First, from inspection, there is no obvious discontinuity in the assignment variable at zero. Nor is there any obvious bunching of the assignment variable distribution to either side of the cut-off. This provides suggestive evidence that the engineers of the insurance firm that supplies all vehicles to the auctioneer and who determine each vehicles $P A V$, do not manipulate these assessments to lie to one side of the assignment cut-off. ${ }^{28}$

Second, the distribution of the assignment variable is bunched at multiples of $£ 50$. Due to this bunching, when we formally test for whether the assignment variable is smooth at the cut-off value using the test proposed in McCrary [2007], we reject the null. To our knowledge, no test currently exists to check for discontinuities in the assignment variable in the case where the assignment variable is bunched. More reassuringly, when we implement McCrary's test for other covariates in $Z_{i}$, that are not bunched at fixed intervals, we accept the null of there being no discontinuity in each covariate at conventional levels of significance.

The third set of evidence we provide on the credibility of the RD design relates to differential endogenous sorting by bidders into auctions either side of the cut-off. The econometric concern is that if experienced bidders are aware of the discontinuity between $P A V_{i}$ and $R_{i}$ then such bidders might be more likely to enter auctions just below the discontinuity where reserve prices are generally set to be low in nearly all the RD regimes we consider. Such selective entry would confound the RD estimates that are evaluated at the discontinuity.

This concern is ameliorated because $P A V_{i}$ is nowhere reported on the auction website, and even within a vehicle category, the mapping between $P A V_{i}$ and $R_{i}$ changes over time. To provide further evidence, Figure A1D shows the average win rate of auction entrants in regime Cat-C1 auctions, in bin widths of 50 over the range \pm 500 of the assignment variable against the mid-point of each bin. Just to the left of the discontinuity, there is no evidence of a bunching of higher win rates among bidders. Rather win rates are falling as $P A V_{i}$ rises. The discontinuity in win rates among bidders occurs precisely at the discontinuity, not to its immediate left.

\section{A.2 Robustness Checks on the Baseline RD Estimates}

Table A3 presents a series of robustness checks on the baseline RD estimates of the reserve price effects in auctions from regime Cat-C1. These are divided into two types relating to: (i) samples and placebo discontinuities (Panel A); (ii) bandwidth and kernel choices (Panel B).

Column 1 of Panel A restricts the sample to auctions with strictly more than one bidder. We

\footnotetext{
${ }^{27}$ The bandwidth chosen is Silverman's [1986] optimal bandwidth that is equal to $1.06 n^{-\frac{1}{5}} \min \left(s, \frac{I Q R}{1.34}\right)$ where $n$ is the sample size, $s$ is the standard deviation of $P A V$, and $I Q R$ is the interquartile range of $P A V$.

${ }^{28}$ While our analysis focuses exclusively on the $90 \%$ of auctioned vehicles that originate from one large insurer, the remaining vehicles auctioned by the same auctioneer are actually supplied by private sellers. Private sellers can choose whether to set a reserve price and whether to publicly announce the reserve. Conditional on vehicle characteristics, we find reported pre-accident values to not be significantly different between vehicles supplied by the insurer and vehicles supplied by private sellers who also use a public reserve price.
} 
find that in such auctions the reserve price effect on winning bids is larger and the effect on the number of bidders is smaller than in the baseline estimates. Both estimates remain significant at the $1 \%$ level. Column 2 restricts the baseline sample to a narrower window around the cut-off using values of the assignment variable between the median above and below the cut-off value. The baseline results are robust to using this more restricted sample that does not utilize information from vehicles with $P A V_{i}$ far away from the discontinuity, and that arguably better captures the spirit of RD designs [Lemieux and Milligan 2008]. Columns 3 and 4 consider placebo cut-offs at the median quantile above and below the true cut-off, respectively. Reassuringly we find no evidence of a change in auction outcomes around these points.

In Columns 5 and 6 of Panel B we present RD estimates based on bandwidths that are half of, and double the size used for the baseline estimates respectively. For both outcomes, the baseline results are robust to these alternative bandwidth choices. Column 7 shows the baseline results to be robust to using a rectangular kernel. For both outcomes the standard errors are smaller than those reported in the baseline estimates using a triangular kernel. ${ }^{29}$ Finally, Column 8 follows the suggestion in Lee and Card [2008] in the case of a discrete assignment variable, of block bootstrapping the standard errors by the value of the assignment variable. Doing so, as expected the standard errors rise relative to the baseline specification for both outcomes, although the estimated effects remain significant at the $1 \%$ level.

\section{A.3 External Validity}

A limitation of $\mathrm{RD}$ designs is that they effectively identify a weighted average treatment effect of $W_{i}$, where the weight is proportional to the ex ante likelihood that an individual realization of $P A V_{i}$ will be close to the cut-off [Lee and Lemieux 2010]. In our setting there is no particular economic significance to basing our RD estimates around the $P A V_{i}=£ 1500$ cut-off. We therefore bolster the external validity of our findings using two strategies: (i) we exploit the variation over time within a vehicle category to present difference-in-difference estimates of the impact of changes in reserve price on auction outcomes; (ii) we exploit data from Category-C auctions that have taken place between December 2008 and June 2010, in which all aspects of the auction environments are unchanged except that the discontinuity between $P A V_{i}$ and $R_{i}$ occurs at $P A V_{i}=£ 2000$.

\section{A.3.1 Difference-in-Difference Estimates}

We exploit the variation over time within a vehicle category to present difference-in-difference (DD) estimates of the impact of changes in reserve price on auction outcomes. For example, the switch from regime Cat-C3 to Cat-C2 has the properties that: (i) for vehicles with $P A V_{i}<£ 1500$,

\footnotetext{
${ }^{29}$ This result is replicated if we use alternative kernels such as an Epanechnikov kernel or use Silverman's [1986] rule-of-thumb bandwidth selection formula which is the optimal bandwidth choice assuming the actual density and kernel are Gaussian.
} 
over time $\Delta R_{i t}=\left(.08 \times P A V_{i}\right)-5$; (ii) for vehicles with $P A V_{i} \geq £ 1500, \Delta R_{i t}=0$. This allows us to infer the same marginal effect of reserve prices on auction outcomes as in the RD design, but exploiting time variation in $R_{i t}$ that occurs for vehicles over the entire range of auctions in which $P A V_{i}<£ 1500$, rather than a specific jump in $R_{i}$ around the $P A V_{i}=£ 1500$ cut-off. We focus on estimating reserve price effects on winning bids, the number of bidders, and the probability the vehicle remains unsold. We do so considering three switches of regime: from Cat-C2 to Cat-C1, from Cat-C3 to Cat-C2, and from Cat-B2 to Cat-B1.

Denote the outcome in auction $j$ for a vehicle of model $m$ on date $t$ as $y_{j m t} . Z_{i}$ and $Z_{t}$ denote vehicle and time varying characteristics. $Z_{i}$ refers to the set of observables controlled for in (6). Consider then estimating reserve price effects using the switch from Cat-C2 to Cat-C1. We then define $C_{t}^{j}$ to be a dummy variable equal to one if regime Cat-C1 is in place on date $t$, and zero if regime Cat-C2 is in place. Whether and how reserve prices change between the regimes depends on whether the pre-accident value for the vehicle, $P A V_{j m t}$, is above or below the $£ 1500$ cut-off. We therefore define a dummy variable $D P A V_{j m t}$ set equal to one if $P A V_{j m t}<£ 1500$, and zero if $P A V_{j m t} \geq £ 1500$. We then estimate the following panel data specification,

$$
\log y_{j m t}=\alpha_{m}+\beta_{0} C_{t}^{j}+\beta_{1} D P A V_{j m t}+\beta_{2}\left[C_{t}^{j} \times D P A V_{j m t}\right]+\Gamma_{j} \mathbf{Z}_{j}+\Gamma_{t} Z_{t}+u_{j m t}
$$

where $\alpha_{m}$ are model fixed effects, and $\mathbf{Z}_{j}$ is a matrix of characteristics of vehicle $j$, and monthly $\mathrm{UK}$ scrap metal prices are in $Z_{t}$. To reduce concerns that we pick up time trends, we restrict the sample to a six month window, split equally either side of the date of the regime switch. $\beta_{0}$ captures any time effects on $\log y_{j m t}$ over this narrow window switching from Cat-C2 to Cat-C1. $\beta_{1}$ captures the differential effect on the outcome of the vehicle being above or below the $P A V_{j m t}=£ 1500$ cut-off. The parameter of interest is $\beta_{2}$, that measures the difference-in-difference effect of the vehicle being above or below the $P A V_{j m t}=£ 1500$ cut-off with the switch from one reserve price regime to the other, $\Delta R_{i t}{ }^{30}$

For outcomes on winning amounts and the probability the vehicle remains unsold we estimate (7) using OLS. On the number of bidders, a specification analogous to (7) is estimated using a Poisson fixed effects model. In the OLS specifications, $u_{j m t}$ is clustered by auction closing date to allow for unobserved factors that are contemporaneously correlated across auctions.

Table A4 presents the results. The first three columns show auction outcomes as we move from the Cat-C2 to Cat-C1 regimes. This change corresponds to an increase in the reserve price of $£ 35$ for all vehicles with $P A V_{j m t}<1500$, and the reserve price is unchanged for all other vehicles. In Column 1 we then see that: (i) there is a naturally declining time trend in winning amounts as we move from the Cat-C2 to Cat-C1 regimes $\left(\widehat{\beta}_{0}<0\right)$; (ii) vehicles with $P A V_{j m t}<1500$ and lower reserve prices have lower winning bids $\left(\widehat{\beta}_{1}<0\right)$; (iii) most importantly, there is a differential

\footnotetext{
${ }^{30} \mathrm{As} D P A V_{j m t}$ is a dummy variable, it is possible to also control for $P A V_{j m t}$. The reported results are robust to doing so as well as also including higher order polynomials in $P A V_{j m t}$.
} 
time trend in winning amounts with the change in regime for vehicles for which there is change in

reserve price $\left(\widehat{\beta}_{2}>0\right)$. At the foot of the table we report the implied marginal change in winning bid with respect to a $£ 1$ change in reserve price, evaluated at the mean $P A V_{j m t}$ conditional on $P A V_{j m t}<£ 1500$. This implied marginal reserve price effect, $£ 1.65$, evaluated at this lower $P A V_{j m t}$ is far larger than that implied by the RD estimate reported in Table 4 that is evaluated at $P A V_{i}=1500$. Taken together, this suggests the marginal effect of the reserve price on winning amounts is decreasing in the underlying valuation of the vehicle.

On the other margins of behavior, Column 2 shows that there is a significant fall in the number of bidders as the reserve price rises. The marginal effect reported at the foot of Table A4 and which is evaluated at a relatively low mean reserve price - that corresponds to the average reserve conditional on $P A V_{j m t}<£ 1500$ - is actually almost identical to the marginal effect derived from the RD estimates. Column 3 shows a very similar pattern of results on the likelihood the vehicle remains unsold at first auction and again the sign, magnitude and significance of the implied marginal effect lines up well with the RD estimates.

The remaining Columns of Table A4 focus on the two other changes in regime. Columns 4 to 6 show the difference-in-difference estimates based on the switch from Cat-C3 to Cat-C2 in which $\Delta R_{i}=-£ 62$ for all vehicles with $P A V_{i}<£ 1500$, and $\Delta R_{i}=0$ for all vehicles with $P A V_{i} \geq £ 1500$. Note that for vehicles with $P A V_{i}<£ 1500$, the sign of the change in reserve prices exploited for the DD estimates is negative. In contrast, the sign of the change in reserve prices exploited for the RD estimates was positive. The results are broadly in line with the DD estimates from the regime switch from Cat-C2 to Cat-C1. We again find that relative to the RD estimates, the implied marginal reserve price effect on the winning bid to be larger when evaluated at this lower reserve, but that the marginal effects on the number of bidders and likelihood the vehicle remains unsold to be almost identical across DD and RD estimates.

Finally, Columns 7 to 9 show the difference-in-difference estimates based on the switch from Cat-B2 to Cat-B1 in which $\Delta R_{i}=£ 35$ for all vehicles with $P A V_{i}<£ 1500$, and $\Delta R_{i}=0$ for all vehicles with $P A V_{i} \geq £ 1500$. In contrast to the $\mathrm{RD}$ estimates in Table 4 , we see that the change in reserve price at evaluated at such a low reserve price for Cat-B vehicles does have a significant impact on the winning bid. In line with the RD estimates, the reserve price effect significantly reduces the number of bidders, and the marginal effect is larger in absolute value than the RD estimates. Finally, the DD estimates, like the RD estimates, show there to be no reserve price impact on the likelihood the vehicle remains unsold for such low value Cat-B vehicles.

\section{A.3.2 Exploiting a Discontinuity in Reserve Price at a Different PAV}

From December 2008 onwards, the reserve price algorithm for Category-C vehicles has been such that: (i) $R_{i}=£ 5$ if $P A V_{i}<£ 2000$; (ii) $R_{i}=.08 P A V_{i}$ if $P A V_{i} \geq £ 2000$. Hence there exists a discontinuous jump in $R_{i}$ from $£ 5$ to $£ 160$ at $P A V_{i}=£ 2000.21 \%$ of auctions in this period are of 
vehicles with $P A V_{i} \geq £ 2000$. Table A5 reports the estimated reserve price effects on winning bids, the number of entrants, and the likelihood the vehicle remains unsold using this discontinuity. As a point of comparison, Column 1 shows the previous baseline estimates from the Cat-C1 RD regime. Column 2 shows that when the discontinuity occurs at the higher $P A V_{i}$ of $£ 2000$, there still exists a significant reserve price effect on winning bids. The magnitude of the implied marginal effect is larger than the baseline estimate. This is in line with the previous evidence that reserve price effects are larger when the reserve price is lower to begin with. However, this effect is estimated less precisely than the baseline amounts both because of the smaller sample size, and the fact that the bulk of the distribution of $P A V$ in this regime (80\%) lies predominantly below the cut-off at $£ 2000$. On the other margins, the reserve price effects are of the anticipated sign, although neither is estimated precisely. As a further falsification check on the earlier results, Column 3 presents evidence of there being jumps in outcome in this latest Cat-C around $P A V_{i}=£ 1500$ that was previously exploited for the baseline estimates in Table 3. Reassuringly, the evidence suggests there is no natural jump in outcomes at this threshold on any margin.

\section{A.4 Re-auctions}

To estimate the last component of (5) requires using data from second auctions. In our data each vehicle has a unique identifier and so we can track when a vehicle comes up for second, or higher, auction. The median time to second auction is four days for Cat-C1 vehicles, and the vast majority of second time auctions have a reserve price set of $£ 5$. Table A6 presents descriptive evidence on first and second time auctions for the Cat-C1 regime. Around $4 \%$ of cars are unsold at first auction. At second auction, $99 \%$ of them are sold. As expected, given the lower reserve price, winning amounts are significantly lower in second auctions. Given the short time frame between first and second auctions, and the lower reserve price in the second auction, bidders might have an incentive to delay their participation in the original auction [McAfee and Vincent 1997]. A dynamic analysis of bidding behavior across auctions lies outside the scope of this paper, but we note that as shown in Table A6: (i) only slightly fewer bidders enter second auctions relative to first auctions; (ii) there are significantly fewer second auctions in which only one bidder enters; (iii) the win rate among bidders does not significantly differ across first or second auctions.

Denote the winning bid in a second-time auction $j$ for a vehicle of model $m$ in time period $t$ as $w_{2 j m t}$. The vehicle has observable characteristics $Z_{j}$, including its model $m$. We then estimate how the winning bid in the re-auction is correlated to the reserve price for the same vehicle in its first time auction, $R_{1 j m t}$, using the following panel data model,

$$
\log w_{2 j m t}=\alpha_{m}+\beta_{t}+\Pi \mathbf{Z}+\gamma R_{1 j m t}+u_{j m t},
$$

where $\alpha_{m}$ and $\beta_{t}$ are model and time fixed effects respectively, $\mathbf{Z}$ is the matrix of other observ- 
able characteristics of the vehicle. Robust standard errors clustered by auction closing date are calculated. The parameter of interest is the elasticity $\gamma$, which maps back to $\frac{\Delta E\left[\pi \mid P A V=P A V_{c}, S=0\right]}{\Delta R_{i}}{ }^{31}$

The results are presented in Table A7. Column 1 shows that the unconditional correlation between the first-time reserve price and the second time winning bid is .343, and this is significantly different from zero. Column 2 shows this correlation to be almost the same magnitude, and estimated more precisely when the full set of covariates is controlled for. Column 3 shows $\widehat{\gamma}$ not to be significantly different between vehicles whose $P A V$ is above or below the $£ 1500$ cut-off used for the RD estimates. In conclusion, the baseline estimate from Column 2 implies the marginal effect of a $£ 1$ increase in the reserve price at first auction corresponds to an increased winning bid of $£ .24$ at first re-auction. This estimate of $\frac{\Delta E\left[\pi \mid P A V=P A V_{c}, S=0\right]}{\Delta R_{i}}$ is then used to calibrate (5).

\section{References}

[1] Association of British insurers (2007) Code of Practice for the Disposal of Motor Vehicle Salvage, Association of British Insurers: London.

[2] ATHEy.s.C, J.LEvin And E.SeIRA (2011) "Comparing Open and Sealed Bid Auctions: Theory and Evidence from Timber Auctions," Quarterly Journal of Economics 126: 207-57.

[3] BAJARI.P And A.hortacsu (2003) "The Winner's Curse, Reserve Prices, and Endogenous Entry: Empirical Insights from eBay Auctions," Rand Journal of Economics 34: 329-55.

[4] BAJARI.P AND A.HORTACSU (2004) "Economic Insights from Internet Auctions," Journal of Economic Literature 42: 457-86.

[5] BARrymore.n And Y.RAVIV (2009) The Effect of Different Reserve Prices on Auction Outcomes, mimeo Claremont McKenna College.

[6] Brown.J And J.morgan (2009) "How Much is a Dollar Worth? Tipping Versus Equilibrium Coexistence on Competing Online Auction Sites," Journal of Political Economy 117: 668-700.

[7] BUlow.J And P.Klemperer (1996) "Auctions Versus Negotiations," American Economic Review 86: 180-94.

[8] CAi.H, J.RILEy AND Y.LIXIN (2007) "Reserve Price Signaling," Journal of Economic Theory 135: $253-68$.

\footnotetext{
${ }^{31}$ The controls include the $\log$ of the pre-accident value, $\log$ of the indicated mileage, dummies for whether the vehicle uses petrol rather than diesel fuel, whether it is manual transmission, whether the keys are available, whether a service history is available, whether the V5 logbook is available, whether it is an EU import, the log of the number of words describing damage to the vehicle recorded on the auction web page, a series of dummies for each year of manufacture, and dummies for the salvage year at which the vehicle is located.
} 
[9] EBAY (2009) Annual Report, http://investor.ebay.com/annuals.cfm.

[10] Fan.J And I.GiJbels (1996) Local Polynomial Modelling and Its Applications, Chapman and Hall: London.

[11] HAHN.J, P.T AND W.VAN DER KLAAUW (2001) "Identification and Estimation of Treatment Effects with a Regression-Discontinuity Design," Econometrica 69: 201-09.

[12] Harrison.G.w (1989) "Theory and Misbehavior of First-Price Auctions," American Economic Review 79: 749-62.

[13] Hausman.J.A, B.Hall And Z.Griliches (1984) "Econometric Models for Count Data with an Application to the Patents-R\&D Relationship," Econometrica 52: 909-38.

[14] HEndRICKS.K AND R.H.PORTER (2007) "An Empirical Perspective on Auctions," Handbook of Industrial Organization Vol.3, M.Armstrong and R.Porter (eds.), Elsevier.

[15] horstmann.I.J And C.LACASse (1997) "Secret Reserve Prices in a Bidding Model with a Resale Option," American Economic Review 87: 663-84.

[16] Hortacsu.A, B. De los Santos And M.wildenbeest (2012) "Testing Models of Consumer Search Using Data on Web Browsing and Purchasing Behavior," American Economic Review 102: $2955-80$.

[17] imbens.G.W And t.lemieux (2008) "Regression Discontinuity Designs: A Guide to Practice," Journal of Econometrics 142: 615-35.

[18] KAGEL.J (1995) "Auctions: A Survey of Experimental Research," in Handbook of Experimental Economics, J.Kagel and A.Roth (eds.), Princeton University Press: Princeton, NJ.

[19] KatKar.R AND D.H.Reiley (2006) "Public Versus Secret Reserve Prices in eBay Auctions: Results from a Pokemon Field Experiment," Advances in Economic Analysis and Policy, Vol. 2 , Article 7.

[20] LEE.D.S AND D.CARD (2008) "Regression Discontinuity Inference with Specification Error," Journal of Econometrics 142: 655-74.

[21] Lee.D.S AND T.Lemieux (2010) "Regression Discontinuity Designs in Economics," Journal of Economic Literature 48: 281-355.

[22] Lemieux.T And K.milligan (2008) "Incentive Effects of Social Assistance: A Regression Discontinuity Approach," Journal of Econometrics 142: 807-28.

[23] Levin.D And J.L.Smith (1994) "Equilibrium in Auctions with Entry," American Economic Review 84: 585-99. 
[24] MCAFEE.R.P And D.vincent (1997) "Sequentially Optimal Auctions," Games and Economic Behavior 18: 246-76.

[25] MCCRARY.J (2008) "Manipulation of the Running Variable in the Regression Discontinuity Design: A Density Test," Journal of Econometrics 142: 698-714.

[26] Milgrom.P AND R.J.Weber (1982) "A Theory of Auctions and Competitive Bidding," Econometrica 50: 1089-122.

[27] Myerson.r (1981) "Optimal Auction Design," Mathematics of Operations Research 6: 58-73.

[28] ockenfels.A, D.H.REILEy AND A.SAdRIEH (2007) "Online Auctions," in Handbook of Information Systems and Economics, Terrence Hendershott (ed.), Elsevier Science.

[29] ostrovsky.m And M.schwarz (2009) Reserve Prices in Internet Advertising Auctions: A Field Experiment, mimeo Stanford University.

[30] PAARSCH.H (1997) "Deriving an Estimate of the Optimal Reserve Price: An Application to British Columbia Timber Sales," Journal of Econometrics 78: 333-57.

[31] PaARSCh.H And H.Hong (2006) An Introduction to the Structural Econometrics of Auction Data, MIT Press: Cambridge MA.

[32] Pinske.J AND G.TAN (2005) "The Affiliation Effect in First Price Auctions," Econometrica 73: $263-67$.

[33] REILEy.D.H (2006) "Field Experiments on the Effects of Reserve Prices in Auctions: More Magic on the Internet," RAND Journal of Economics 37: 195-211.

[34] Riley.J And W.SAmuelson (1981) "Optimal Auctions," American Economic Review 71: 381-92.

[35] Roberts.J.w (2013) "Unobserved Heterogeneity and Reserve Prices in Auctions," RAND Journal of Economics 44: 712-32.

[36] Roberts.J.W And A.sweeting (2011) Competition Versus Auction Design, mimeo, Duke University.

[37] RosenkRanz.S And P.w.schmitz (2007) "Reserve Prices in Auctions as Reference Points," Economic Journal 117: 637-53.

[38] Silverman.B (1986) Density Estimation for Statistics and Data Analysis, Chapman Hall: London. 
[39] Tan.G And O.Yilankaya (2006) "Equilibria in Second Price Auctions With Participation Costs," Journal of Economic Theory 130: 205-19.

[40] Vincent.D.R (1995) "Bidding Off the Wall: Why Reserve Prices May Be Kept Secret," Journal of Economic Theory 65: 575-84. 


\section{Table 1: Impacts of Reserve Prices $(R)$ on Second-price Auction Outcomes}

\section{$\partial \mathrm{E}[$ revenue | sold $] / \partial \mathrm{R} \quad \partial \mathrm{Prob}[$ sold $] / \partial \mathrm{R} \quad \partial \mathrm{E}[$ \# of actual bidders $] / \partial \mathrm{R}$}

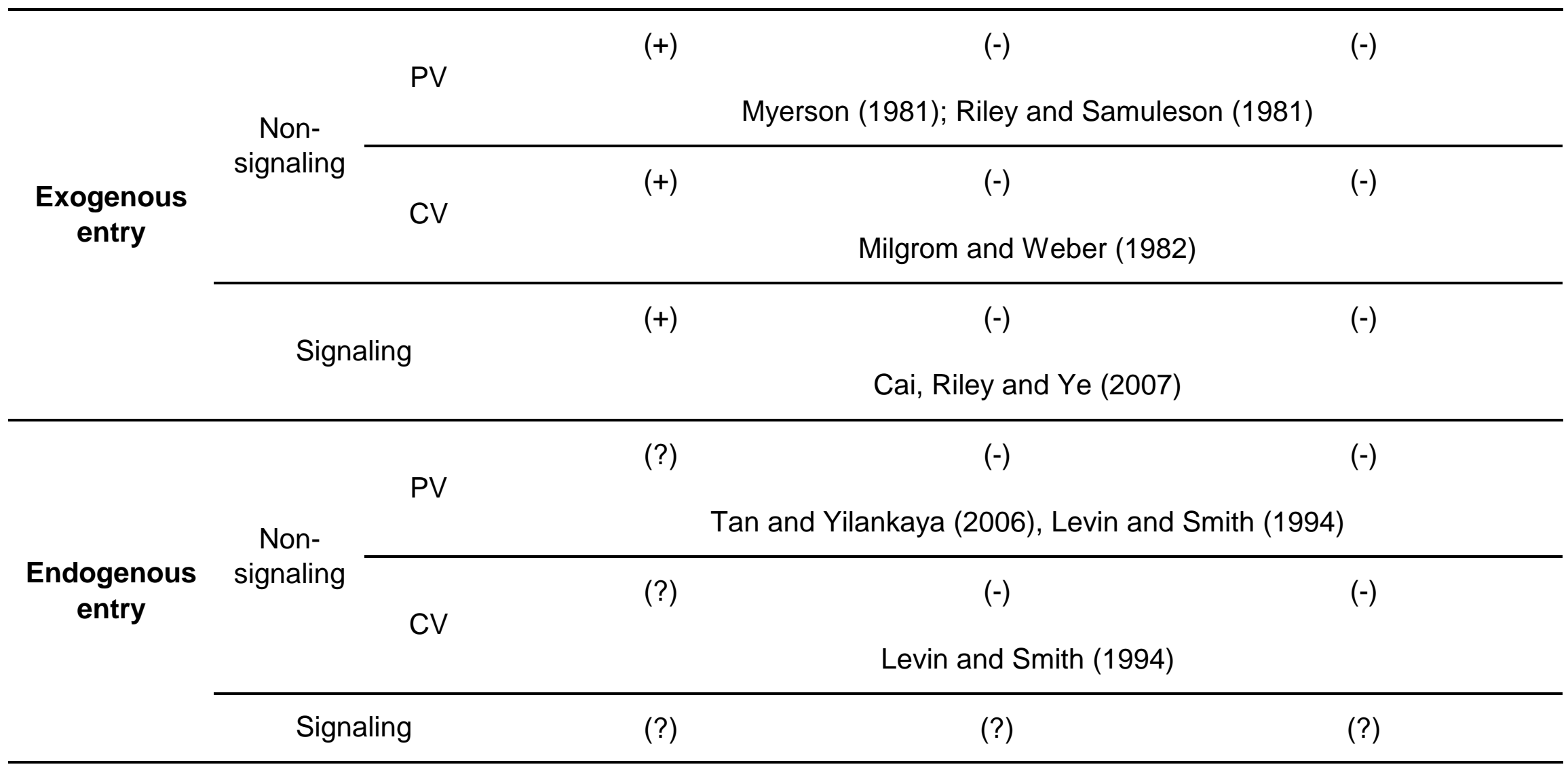

Notes: In the exogenous (endogenous) entry model, the number of potential bidders are exogenously (endogenously) determined (stochastic/nonstochastic). In the endogenous entry model, bidders' entry decisions are affected by reserve prices. Signaling (non-signaling) models refer to those in which reserve prices (do not) convey valuation-related information of vehicles, which is not available to bidders. 


\section{Table 2: Reserve Price Regimes}

\section{Category C Vehicles}

\section{Category B Vehicles}

(1) Regime 1 (Baseline)

(3) Regime 3

(4) Regime 1
Reserve Price $=8 \%$ of PAV

No jump at $P A V=1500$

$$
\mathrm{PAV}=\{1500
$$

40

Form of Discontinuity in Reserve Price at
$P A V=£ 1500$ :

Reserve Price for Vehicles with PAV $>£ 1500$ Reserve Price $=8 \%$ of PAV

Reserve Price $=8 \%$ o

$$
\text { PAV }
$$

$$
40
$$

Jumps down from 40 to

Percentage of Auctions with $\mathrm{PAV}<1500$

.437
Reserve Price $=8 \%$ of PAV

.459
(5) Regime 2

5

No jump at $P A V=1500$

499

\begin{tabular}{|c|c|c|c|c|c|c|}
\hline Time Period & 10 July 2006 - 17 Nov 2008 & 1 Feb 2005 - 7 July 2006 & 2 Jan 2003 - 31 Jan 2005 & 8 Aug $2006-17$ Nov 2008 & 27 Sept 2004 - 7 Aug 2006 & 2 Jan $2003-17$ Nov 2008 \\
\hline Number of First Time Auctions & 60061 & 44734 & 45066 & 21296 & 22631 & 64280 \\
\hline
\end{tabular}

Category D Vehicles

(6) Regime 1

6006

2263

6428

Notes: All statistics refer to vehicles that are being auctioned for the first time. A Category B Vehicle is a Salvaged Vehicle which is so structurally damaged or devoid of parts that it is not possible to repair it economically or safely. A Category C Vehicle is a Salvaged pre-accident vas pre-accident value thereof. Each Column represents a different regime in which the relationship between the pre-accident value
include proxy bids. The pre-accident value refers to an engineer's valuation of the vehicle prior to it being involved in any accident. 
Table 3: Auction Outcomes, by Discontinuity Regime

Means, standard deviation in parentheses

Category C Vehicles

Category B Vehicles
(2) Regime 2
(4) Regime 1
(1) Regime 1 (Baseline)

(2) Regime 2

(3) Regime 3

Jumps down from 40 to 5 at PAV $=1500$

o jump at $P A V=1500, R=5$

Form of Discontinuity in Reserve Price:

$$
\begin{array}{ll}
\text { at PAV }=1500 & \text { at PAV }=1500
\end{array}
$$

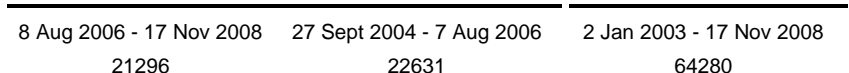

Number of First Time Auctions

60061

44734

45066

21296

22631

A. Auction Outcomes

Winning Bid (£)

Winning Amount / Reserve Price

Number of Bidders

Percentage of Auctions With One Bidder

Vehicle Unsold [Yes $=1$

B. Bidder and Bid Characteristics

Number of Unique Winners

Number of Unique Bidders

Win Rate of Winning Bidders

Win Rate Among All Bidders

Percentage of Winners that Report Being Private Buyers Number of Bids Placed

$\begin{array}{cc}501 & 419 \\ (1088) & (950) \\ 2.85 & 12.2 \\ (3.21) & (37.8) \\ 4.49 & 4.06 \\ (3.14) & (2.98) \\ .069 & .085 \\ (.254) & (.279) \\ .042 & .073 \\ (.201) & (.260) \\ & \\ 3156 & 1791 \\ 4862 & 2335 \\ .281 & .297 \\ (.147) & (.149) \\ .222 & .238 \\ (.082) & (.087) \\ 23.2 & 0 \\ 13.8 & 10.6 \\ (17.0) & (12.2)\end{array}$

\section{Web Views}

Number of bidders that view the webpage at least once 73.9

Number of bidders that view the webpage at least 5 times

(71.8)

6.64

Number of bidders that view the webpage at least 10 times

510
$(1040)$
2.67
$(17.6)$
2.88
$(2.92)$
.203
$(.402)$
.248
$(.432)$

1429
1739
.313
$(.165)$
.264
$(.114)$
Not available
7.76
$(11.2)$

$\begin{array}{ccc}229 & 183 & 1562 \\ (399) & (342) & (2706) \\ 36.7 & 36.6 & 2.73 \\ (81.5) & (68.9) & (9.70) \\ 3.39 & 3.28 & 6.88 \\ (2.00) & (1.91) & (4.90) \\ .094 & .079 & .053 \\ (.291) & (.270) & (.224) \\ .020 & .039 & .054 \\ (.142) & (.193) & (.225) \\ & & \\ 374 & 374 & 3890 \\ 492 & 423 & 5801 \\ .315 & .343 & .273 \\ (.134) & (.145) & (.158) \\ .267 & .291 & .193 \\ (.067) & (.086) & (.079) \\ 1 & 0 & 23.1 \\ 8.27 & 7.45 & 22.0 \\ (8.96) & (7.27) & (21.7) \\ & & \end{array}$

562

(9.70)

6.88

.224)

(225)

3890

.193

23.1

11.4

$1.73-10.2$

(.584)
(13.2)

(1.35) 
Table 4: Bidders' Behavior - RD Estimates of Reserve Price Effects

Non Parametric Regression Discontinuity Results

Bootstrapped standard errors in parentheses, based on 50 replications

\begin{tabular}{|c|c|c|c|c|c|c|}
\hline & & ategory C Vehicles & & Category B & Vehicles & Category D Vehicles \\
\hline & $\begin{array}{l}\text { (1) Regime } 1 \\
\text { (Baseline) }\end{array}$ & (2) Regime 2 & (3) Regime 3 & (4) Regime 1 & (5) Regime 2 & (6) Regime 1 \\
\hline Form of Discontinuity in Reserve Price: & $\begin{array}{l}\text { Jumps up from } 40 \\
\text { to } 120 \text { at } P A V=1500\end{array}$ & $\begin{array}{l}\text { Jumps up from } 5 \text { to } \\
120 \text { at } P A V=1500\end{array}$ & $\begin{array}{l}\text { No jump at } \\
P A V=1500\end{array}$ & $\begin{array}{c}\text { Jumps down from } 40 \\
\text { to } 5 \text { at } P A V=1500\end{array}$ & $\begin{array}{c}\text { No jump at } \\
\text { PAV }=1500, R=5\end{array}$ & No jump at $P A V=1500$ \\
\hline Auction Outcome & & & & & & \\
\hline A.Winning Bid & $33.6^{* \star *}$ & $40.4^{\star \star \star}$ & -3.34 & 2.60 & -2.31 & -2.28 \\
\hline & $(3.80)$ & $(5.50)$ & $(4.49)$ & $(4.13)$ & $(2.78)$ & $(4.88)$ \\
\hline Implied $\Delta$ Outcome $/ \Delta \mathbf{R}$ & $.420^{* * *}$ & $.351^{\star * *}$ & & -.074 & & \\
\hline & {$[.336, .504]$} & {$[.267, .435]$} & & {$[-.328, .179]$} & & \\
\hline B. Number of Bidders & $-1.33^{\star \star *}$ & $-2.13^{\star \star \star}$ & .001 & $.127^{\star *}$ & -.064 & -.046 \\
\hline & $(.081)$ & $(.070)$ & $(.079)$ & $(.050)$ & $(.054)$ & $(.066)$ \\
\hline Implied $\Delta$ Outcome $/ \Delta \mathbf{R}$ & $-.017^{\star \star \star}$ & $-.018^{\star \star \star}$ & & $-.003^{\star \star}$ & & \\
\hline & {$[-.018,-.016]$} & {$[-.020,-.017]$} & & {$[-.006,-.001]$} & & \\
\hline C. Vehicle Unsold [Yes =1] & $.104^{\star * *}$ & $.244^{* * *}$ & -.002 & -.003 & -.009 & .007 \\
\hline & $(.006)$ & $(.008)$ & $(.005)$ & $(.005)$ & $(.008)$ & $(.008)$ \\
\hline Implied $\Delta$ Outcome $/ \Delta \mathbf{R}$ & $.003^{\star * *}$ & $.002^{* \star *}$ & & .000 & & \\
\hline & {$[.003, .003]$} & {$[.002, .002]$} & & {$[.000, .000]$} & & \\
\hline Number of Auctions & 56959 & 41124 & 33500 & 20646 & 21569 & 60202 \\
\hline
\end{tabular}




\section{Table 5: Seller's Behavior - First Order Condition With Respect to Auction Reserve Price}

\begin{tabular}{|c|c|c|c|c|c|c|c|}
\hline & $\begin{array}{l}\text { (1) Winning Amount, } \\
\text { Re-auction }\end{array}$ & $\begin{array}{l}\text { (2) Winning Amount, } \\
\text { First Auction }\end{array}$ & (3) Probability Unsold & $\begin{array}{l}\text { (4) Marginal effect on } \\
\text { probability unsold }\end{array}$ & $\begin{array}{l}\text { (5) Marginal Effect on } \\
\text { Winning Amount } \\
\text { in Re-auction }\end{array}$ & $\begin{array}{l}\text { (6) Marginal Effect on } \\
\text { Winning Amount }\end{array}$ & $\begin{array}{l}\text { (7) Marginal Effect } \\
\text { on Expected Profit }\end{array}$ \\
\hline$\underline{\text { RD Estimates }}\left(\Delta R_{1}=80\right)$ & $E[\Pi \mid P A V=1500, S=0]$ & $E[\Pi \mid P A V=1500, S=1]$ & $\operatorname{Pr}[S=0 \mid P A V=1500]$ & $\frac{\partial \operatorname{Pr}[S=0 \mid P A V=1500]}{\partial R_{1}}$ & $\frac{\partial E[\Pi \mid P A V=1500, S=0]}{\partial R_{1}}$ & $\frac{\partial E[\Pi \mid P A V=1500, S=1]}{\partial R_{1}}$ & $\frac{\partial E[\Pi \mid P A V=1500]}{\partial R_{1}}$ \\
\hline 1. Cat-C1, Regime $1 \mid \mathrm{PAV}=1500$ & 103 & 242 & .107 & .003 & .113 & .420 & -0.030 \\
\hline 2. Lower bound & 92 & 248 & .094 & .003 & .016 & .336 & -0.162 \\
\hline 3. Upper bound & 114 & 235 & .121 & .003 & .210 & .504 & 0.105 \\
\hline
\end{tabular}

Notes: The components in Columns 1 to 3 are descriptives from the data. The components in Columns 4 and 6 are derived from the documented RD estimates in this Cat-C1 regime. The component in Column 5 is based on the non-experimental estimates from second
time auctions. In Row 2 (3) we calculate the lower (upper) bound on the marginal effect on profits using the appropriate values at the edge of the relevant $95 \%$ confidence interval for estimated values. 
Table 6: Reserve Price Effects on Novel Margins of Bidder's Behavior

\section{Non Parametric Regression Discontinuity Results}

Bootstrapped standard errors in parentheses, based on 50 replications

\section{Category C Vehicles}
(1) Regime 1
(Baseline)
(2) Regime 2

umps up from 5 to

120 at $P A V=1500$
(3) Regime 3

No jump at

\section{Category B Vehicles}

(4) Regime 1

umps down from 40 to 5 at $P A V=1500$
(5) Regime 2

No jump at $P A V=1500, R=5$

\section{Category D Vehicles}

(6) Regime 1

\section{Auction Outcome}

A. Number of Potential Bidders

Implied $\Delta$ Outcome/ $\Delta \mathbf{R}$

B. Number of Bidders That View the Webpage Once

Implied $\Delta$ Outcome $/ \Delta R$

C. All Bidders: Win Rate

Implied $\Delta$ Outcome $/ \Delta R$

D. All Bidders: Months Since Registered

Implied $\Delta$ Outcome $/ \Delta R$

E. Auction Winner: Win Rate

Implied $\Delta$ Outcome $/ \Delta \mathbf{R}$

F. Auction Winner: Months Since Registered

Implied $\Delta$ Outcome $/ \Delta \mathbf{R}$

Number of Auctions

Number of Auctions (Webviews data)

$-.273^{\star \star \star}$
$(.077)$
$-.003^{\star \star *}$
$.005,-.001]$
1.70

1.70

(1.53)

.021

$[-.016, .059]$

$$
.011^{* * *}
$$

(.002)

$.000^{\star \star \star}$

$[.000, .000]$

$2.90^{\star * *}$

(.625)

$.083^{\star \star \star}$

[ $.048, .118$ ]

$.008^{*}$

(.005)

$.0001^{*}$

[ $-.00001, .0002$ ]

$2.50^{\text {** }}$

(1.10)

$.031^{\text {** }}$

[.004, .058 ] $.012^{\star * *}$

(.003)

$.000^{\star * *}$

[.000,.000]

$1.76^{* * *}$

(.447)

$.015^{\star * *}$

$[.008, .023]$

$-.002$

(.005)

$-.000$

[ $-.000, .000]$

$\begin{array}{lc}1.68^{*} & .308 \\ (.909) & (.585) \\ .015^{*} & \end{array}$

\section{.001}

(.003)

$-.093$

(.364)

$-.013^{*}$

(.007)

308
$(585)$

a PAV $=1500$

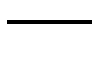

No jump at $P A V=1500$

56959

56959

41124

43855

33500

.409
$(.316)$
-.012
$[-.029, .006]$

$[-.029, .006]$

$\begin{array}{ccc}-.005^{\star} & .002 & -.000 \\ (.003) & (.003) & (.002) \\ .000^{\star} & & \\ {[.000, .000]} & & \\ -.367 & -.024 & -.899 \\ (.734) & (.414) & (.565) \\ .010 & & \end{array}$

\section{$[-.031, .052]$}

$\begin{array}{lcc}-.012^{*} & .002 & .001 \\ (.007) & (.008) & (.005) \\ .0003^{*} & & \end{array}$

[ $-.000, .001]$

$\begin{array}{ccc}-1.08 & .310 & -1.51^{\star} \\ (.954) & (.627) & (.869)\end{array}$
parametric regression using a rectangular kernel, where the bandwidth is set is chosen to give positive weight to at least 30 observations on each side of the discontinuity when estimating the conditional mean at the cut-off. Bootstrapped standard errors based on 50 replications are shown. A Category B Vehicle is a Salvaged Vehicle which is so structurally damaged or devoid of parts that it is not possible to repair it economically or safely. A Category C Vehicle is a Salvaged Vehicle which is damaged to the extent that the retail cost of repair to the vehicle exceeds the retail pre-accident value thereof. A Category D Vehicle is a Salvaged Vehicle which is damaged to the extent that the retail cost of repair to the vehicle does not exceed the retail pre-accident value thereof. Each Column represents a different regime in which the relationship between the pre-accident value (PAV) and the public reserve price (R) varies. The win rate for a given bidder is the fraction of past 
Table A1: Vehicle Characteristics by Reserve Price Regime

Means, standard deviation in parentheses

\section{Category C Vehicles}

(1) Regime 1 (Baseline)

(2) Regime 2

\section{Category B Vehicles}

(4) Regime 1

(5) Regime 2

Category D Vehicles

(6) Regime 1

Form of Discontinuity in Reserve Price: at $P A V=1500$
No jump at $P A V=1500$
Jumps down from 40 to 5 at $P A V=1500$

No jump at $P A V=1500, R=5 \quad$ No jump at $P A V=1500$

\begin{tabular}{|c|c|c|c|c|c|c|}
\hline Time Period & 10 July 2006 - 17 Nov 2008 & 1 Feb 2005 - 7 July 2006 & 2 Jan 2003 - 31 Jan 2005 & 8 Aug 2006 - 17 Nov 2008 & 27 Sept 2004 - 7 Aug 2006 & 2 Jan 2003 - 17 Nov 2008 \\
\hline Number of First Time Auctions & 60061 & 44734 & 45066 & 21296 & 22631 & 64280 \\
\hline \multirow[t]{2}{*}{ Pre-accident Value } & 2442 & 2272 & 2325 & 2389 & 2389 & 4833 \\
\hline & (2988) & (2818) & (2763) & (3398) & (3112) & (5739) \\
\hline \multirow[t]{2}{*}{ Indicated Mileage } & 77534 & 76652 & 75469 & 74677 & 71975 & 59109 \\
\hline & (40351) & (40097) & $(41340)$ & (44006) & (42577) & (39133) \\
\hline \multirow[t]{2}{*}{ Petrol [Yes=1] } & .848 & .864 & .856 & .841 & .847 & .828 \\
\hline & $(.359)$ & $(.343)$ & $(.351)$ & $(.366)$ & $(.360)$ & $(.377)$ \\
\hline \multirow[t]{2}{*}{ Manual Transmission [Yes=1] } & .878 & .897 & .875 & .884 & .895 & .859 \\
\hline & $(.328)$ & $(.303)$ & $(.331)$ & $(.320)$ & $(.307)$ & (.348) \\
\hline \multirow[t]{2}{*}{ Keys Available [Yes=1] } & .940 & .871 & .575 & .874 & .764 & .833 \\
\hline & $(.237)$ & $(.335)$ & (.494) & (.332) & (.425) & $(.373)$ \\
\hline \multirow[t]{2}{*}{ Service History Available [Yes $=1]$} & .170 & .038 & .013 & .124 & .033 & .116 \\
\hline & $(.376)$ & $(.192)$ & $(.114)$ & $(.330)$ & $(.177)$ & $(.320)$ \\
\hline \multirow[t]{2}{*}{ V5 Logbook Available [Yes=1] } & .582 & .243 & .178 & .539 & .237 & .444 \\
\hline & (.493) & (.429) & (.382) & (.499) & (.425) & (.497) \\
\hline \multirow[t]{2}{*}{ EU Import [Yes=1] } & .007 & 0 & 0 & .006 & 0 & .002 \\
\hline & $(.085)$ & (0) & (0) & $(.076)$ & (0) & $(.047)$ \\
\hline \multirow[t]{2}{*}{ Number of Words Describing Damage } & 5.71 & 5.08 & 4.66 & 6.53 & 6.11 & 5.10 \\
\hline & $(4.47)$ & $(4.06)$ & (4.29) & $(5.21)$ & (4.78) & $(4.23)$ \\
\hline Unique Types of Vehicle Make & 49 & 48 & 48 & 48 & 49 & 49 \\
\hline Unique Types of Vehicle Model & 980 & 972 & 922 & 780 & 868 & 1123 \\
\hline
\end{tabular}

Notes: All statistics refer to vehicles that are being auctioned for the first time. A Category B Vehicle is a Salvaged Vehicle which is so structurally damaged or devoid of parts that it is not possible to repair it economically or safely. A Category C Vehicle is a Salvaged Vehicle which is damaged to the extent that the retail cost of repair to the vehicle exceeds the retail pre-accident value thereof. A Category D Vehicle is a Salvaged Vehicle which is damaged to the extent that the retail cost of repair to the vehicle does no exceed the retail pre-accident value thereof. Each Column represents a different regime in which the relationship between the pre-accident value (PAV) and the public reserve price (R) varies. The time period refers to the dates on which this regime is in place. The
number of bids placed included proxy bids. The pre-accident value refers to an engineer's valuation of the vehicle prior to it being involved in any accident. 
Table A2: Correlates of Auction Outcomes

Robust standard errors in parentheses

Category C, Regime 1

Dependent Variable:

(1a) OLS: Log (Winning Bid)

(1b) FE Poisson: Number of Bidders

C) Vehicle Unsold

Log (Pre-accident Value)

Log (Indicated Mileage)

Petrol [Yes=1]

Manual Transmission [Yes=1]

Keys Available [Yes $=1]$

Service History Available [Yes=1]

V5 Logbook Available [Yes=1]

EU Import [Yes=1]

Log (Number of Words Describing Damage)

Month of Auction Dummies (39)

Year of Manufacture Dummies (29)

Salvage Yard Dummies (14)

Model Fixed Effects

Adjusted R-squared

Number of Auctions

\begin{tabular}{|c|c|c|}
\hline $442^{\star \star \star}$ & $.030^{\star \star \star}$ & $.062^{\star \star \star}$ \\
\hline (.018) & $(.006)$ & $(.003)$ \\
\hline $.004^{\star \star}$ & $.007^{\star \star \star}$ & $-.002^{\star \star \star}$ \\
\hline (.002) & $(.001)$ & $(.001)$ \\
\hline $.218^{\star \star \star}$ & $-.215^{\star \star \star}$ & $.023^{\star \star \star}$ \\
\hline (.007) & $(.006)$ & $(.002)$ \\
\hline $.056^{\star \star \star}$ & $-.016^{\star \star}$ & $.006^{\star \star}$ \\
\hline (.007) & $(.007)$ & $(.003)$ \\
\hline $.054^{* \star *}$ & $.076^{\star \star *}$ & $-.018^{\star * *}$ \\
\hline (.009) & $(.009)$ & $(.004)$ \\
\hline $.019^{\star * \star}$ & $-.011^{\star *}$ & .001 \\
\hline (.005) & $(.005)$ & $(.002)$ \\
\hline-.002 & .002 & $-.006^{\star \star \star}$ \\
\hline .004) & $(.004)$ & (.002) \\
\hline $.065^{\star *}$ & $.046^{*}$ & -.005 \\
\hline (.029) & $(.026)$ & $(.011)$ \\
\hline $.062^{\star \star \star}$ & $-.084^{\star \star \star}$ & $.010^{\star \star \star}$ \\
\hline (.003) & $(.003)$ & $(.027)$ \\
\hline Yes & Yes & Yes \\
\hline Yes & Yes & Yes \\
\hline Yes & Yes & Yes \\
\hline Yes & Yes & Yes \\
\hline .820 & - & .078 \\
\hline 55079 & 54911 & 57462 \\
\hline
\end{tabular}

\begin{tabular}{|c|c|}
\hline $\begin{array}{c}\text { Category B, Regime } 1 \\
\text { (2) OLS: Log (Winning } \\
\text { Amount) }\end{array}$ & $\begin{array}{c}\text { Category D } \\
\text { (3) OLS: Log (Winning } \\
\text { Amount) }\end{array}$ \\
\hline $.188^{\star \star \star}$ & $.474^{\star \star \star}$ \\
\hline$(.017)$ & $(.021)$ \\
\hline $.011^{* \star *}$ & $-.010^{\star \star \star}$ \\
\hline$(.002)$ & $(.002)$ \\
\hline$-.205^{\star \star \star}$ & $-.181^{\star \star \star}$ \\
\hline$(.015)$ & $(.006)$ \\
\hline-.022 & $-.018^{\star \star \star}$ \\
\hline$(.015)$ & $(.007)$ \\
\hline $.094^{\star \star *}$ & $.047^{\star \star \star}$ \\
\hline$(.014)$ & $(.006)$ \\
\hline .022 & $.033^{\star * \star}$ \\
\hline$(.014)$ & $(.006)$ \\
\hline$-.039^{* \star *}$ & .004 \\
\hline$(.009)$ & $(.005)$ \\
\hline-.019 & $.105^{\star \star}$ \\
\hline$(.090)$ & $(.047)$ \\
\hline .006 & $-.063^{\star \star *}$ \\
\hline$(.006)$ & $(.003)$ \\
\hline Yes & Yes \\
\hline Yes & Yes \\
\hline Yes & Yes \\
\hline Yes & Yes \\
\hline .649 & .859 \\
\hline 19368 & 54673 \\
\hline
\end{tabular}
insufficient variation in the number of bidders across auctions. In Column 3 we include all first time auctions. The dependent variable is a dummy variable equal to one if no bids are placed in the auction so the vehicle remains unsold, and zero otherwise. 
Table A3: Robustness Checks on the Baseline Results

Non Parametric Regression Discontinuity Results

Bootstrapped standard errors in parentheses, based on 50 replications

A. Samples and Placebos

B. Bandwidth, Kernels and Standard Errors

\begin{tabular}{|c|c|c|c|c|c|c|c|c|}
\hline Outcome Variable & $\begin{array}{l}\text { (1) More Than } \\
\text { One Bidder }\end{array}$ & $\begin{array}{l}\text { (2) Narrow } \\
\text { Window }\end{array}$ & $\begin{array}{l}\text { (3) Placebo Cut-off at } \\
\text { Median Quantile Above } \\
\text { True Cut-off }\end{array}$ & $\begin{array}{l}\text { (4) Placebo Cut- } \\
\text { off at Median } \\
\text { Quantile Below } \\
\text { True Cut-off }\end{array}$ & $\begin{array}{c}\text { (5) Half } \\
\text { Bandwidth }\end{array}$ & $\begin{array}{l}\text { (6) Double } \\
\text { Bandwidth }\end{array}$ & $\begin{array}{l}\text { (7) Rectangular } \\
\text { Kernel }\end{array}$ & $\begin{array}{l}\text { (8) Clustering } \\
\text { Standard Errors }\end{array}$ \\
\hline Winning Bid & $\begin{array}{l}54.3^{* \star *} \\
(3.92)\end{array}$ & $\begin{array}{l}59.5^{\star \star \star} \\
(.387)\end{array}$ & $\begin{array}{l}-16.1 \\
(10.6)\end{array}$ & $\begin{array}{l}-.492 \\
(16.7)\end{array}$ & $\begin{array}{l}34.0^{* \star *} \\
(5.53)\end{array}$ & $\begin{array}{l}45.0^{* \star *} \\
(2.50)\end{array}$ & $\begin{array}{l}32.8^{* \star \star} \\
(3.61)\end{array}$ & $\begin{array}{l}33.6^{* * *} \\
(6.30)\end{array}$ \\
\hline Number of Bidders & $\begin{array}{l}-.888^{\star \star \star} \\
(.064)\end{array}$ & $\begin{array}{l}-.804^{\star \star \star} \\
(.388)\end{array}$ & $\begin{array}{l}-.141 \\
(.107)\end{array}$ & $\begin{array}{l}-.053 \\
(.480)\end{array}$ & $\begin{array}{l}-1.23^{* \star *} \\
(.124)\end{array}$ & $\begin{array}{l}-1.22^{* * *} \\
(.052)\end{array}$ & $\begin{array}{l}-1.35^{* \star *} \\
(.069)\end{array}$ & $\begin{array}{l}-1.33^{* * *} \\
(.085)\end{array}$ \\
\hline Number of Auctions & 52963 & 28885 & 31184 & 25570 & 56959 & 56959 & 56872 & 56959 \\
\hline
\end{tabular}

Notes: ${ }^{* * *}$ denotes significance at $1 \%,{ }^{* *}$ at $5 \%$, and ${ }^{*}$ at $10 \%$. All observations relate to auctions of category C Vehicles in Regime 1 , where there is at least one bidder. Each coefficient is estimated from a separate non parametric regression using a triangular kernel, where the bandwidth is set is chosen to give positive weight to at least 30 observations on each side of the discontinuity when estimating the conditional mean at the cut-off. Bootstrapped standard errors based on 50 replications are shown. In Column 1 we restrict the sample to auctions with strictly more than one bidder. In Column 2 the narrow window is defined as using values of the assignment variable between the median above and below the cut-off value. The bandwidths in Columns 5 and 6 are set to half and double the value that gives positive weight to at least 30 observations on each side of the discontinuity when estimating the conditional mean at the cut-off. In Column 7 a rectangular kernel is used. In Column 8 the standard errors are block bootstrapped by the value of the assignment variable. 
Table A4: Difference in Difference Specifications

Robust standard errors in parentheses clustered by auction closing date in all columns except for number of bidders

\begin{tabular}{|c|c|c|c|c|c|c|c|c|c|}
\hline \multirow{2}{*}{$\begin{array}{l}\text { RD Regime Change: } \\
\text { Dependent Variable: }\end{array}$} & \multicolumn{3}{|c|}{$\begin{array}{l}\text { Category C RD Regime } 2 \text { to RD Regime } 1 \\
\qquad(\triangle R=£ 35)\end{array}$} & \multicolumn{3}{|c|}{$\begin{array}{c}\text { Category C RD Regime } 3 \text { to RD Regime } 2 \\
\qquad(\Delta R=-\{62)\end{array}$} & \multicolumn{3}{|c|}{$\begin{array}{l}\text { Category B RD Regime } 2 \text { to RD Regime } 1 \\
\qquad(\triangle R=£ 35)\end{array}$} \\
\hline & (1) Winning Bid & $\begin{array}{l}\text { (2) Number of } \\
\text { Bidders }\end{array}$ & (3) Vehicle Unsold & (4) Winning Bid & $\begin{array}{l}\text { (5) Number of } \\
\text { Bidders }\end{array}$ & (6) Vehicle Unsold & (7) Winning Bid & $\begin{array}{l}\text { (8) Number of } \\
\text { Bidders }\end{array}$ & (9) Vehicle Unsold \\
\hline Category C RD Regime 1 & $\begin{array}{l}-.271^{\star \star \star} \\
(.010)\end{array}$ & $\begin{array}{l}-.042^{* * *} \\
(.005)\end{array}$ & $\begin{array}{l}-.018^{\star \star \star} \\
(.006)\end{array}$ & & & & & & \\
\hline Pre-accident Value $<£ 1500$ & $\begin{array}{l}-.958^{\star \star \star} \\
(.015)\end{array}$ & $\begin{array}{l}.318^{* \star \star} \\
(.007)\end{array}$ & $\begin{array}{l}-.183^{\star \star \star} \\
(.004)\end{array}$ & $\begin{array}{l}-.566^{\star \star \star} \\
(.013)\end{array}$ & $\begin{array}{l}-.153^{\star \star \star} \\
(.009)\end{array}$ & $\begin{array}{l}.138^{\star \star \star} \\
(.006)\end{array}$ & $\begin{array}{l}-.529^{\star \star \star} \\
(.020)\end{array}$ & $\begin{array}{l}-.151^{\star \star \star} \\
(.011)\end{array}$ & $\begin{array}{l}.011^{* \star \star} \\
(.004)\end{array}$ \\
\hline $\begin{array}{l}\text { Category C RD Regime } 1 \times \text { Pre-accident Value }<£ 1500 \\
{[\Delta R=£ 35]}\end{array}$ & $\begin{array}{l}.536^{\star \star \star} \\
(.016)\end{array}$ & $\begin{array}{l}-.160^{\star \star \star} \\
(.007)\end{array}$ & $\begin{array}{l}.045^{\star \star \star} \\
(.003)\end{array}$ & & & & & & \\
\hline Category C RD Regime 2 & & & & $\begin{array}{l}-.421^{\star \star \star} \\
(.011)\end{array}$ & $\begin{array}{l}-.121^{\star \star \star} \\
(.005)\end{array}$ & $\begin{array}{l}.050^{* \star \star} \\
(.004)\end{array}$ & & & \\
\hline $\begin{array}{l}\text { Category C RD Regime } 2 \times \text { Pre-accident Value }<\varepsilon 1500 \\
\text { [mean } \Delta R=-\{62]\end{array}$ & & & & $\begin{array}{l}-.262^{\star \star \star} \\
(.019)\end{array}$ & $\begin{array}{l}.444^{\star \star \star} \\
(.009)\end{array}$ & $\begin{array}{l}-.371^{\star \star \star} \\
(.006)\end{array}$ & & & \\
\hline Category B RD Regime 1 & & & & & & & $\begin{array}{l}-.058^{\star \star \star} \\
(.016)\end{array}$ & $\begin{array}{l}-.035^{\star \star \star} \\
(.009)\end{array}$ & $\begin{array}{l}-.011^{\star \star \star} \\
(.004)\end{array}$ \\
\hline $\begin{array}{l}\text { Category B RD Regime } 1 \times \text { Pre-accident Value }<£ 1500 \\
{[\Delta R=£ 35]}\end{array}$ & & & & & & & $\begin{array}{l}.500^{\star \star \star} \\
(.021)\end{array}$ & $\begin{array}{l}-.091^{\star \star \star} \\
(.012)\end{array}$ & $\begin{array}{l}-.003 \\
(.004)\end{array}$ \\
\hline Implied $\Delta$ Outcome/ $\Delta R$, evaluated at mean $P A V<1500$ & $\begin{array}{c}1.65^{\star \star \star} \\
{[1.56,1.75]}\end{array}$ & $\begin{array}{c}-.018^{\star \star \star} \\
{[-.019,-.016]}\end{array}$ & $\begin{array}{c}.000^{* \star *} \\
{[.000, .000]} \\
\end{array}$ & $\begin{array}{c}.502^{\star \star \star} \\
{[.430, .574]}\end{array}$ & $\begin{array}{c}-.017^{\star \star \star} \\
{[-.018,-.016]}\end{array}$ & $\begin{array}{c}.002^{\star \star \star} \\
{[.002, .002]}\end{array}$ & $\begin{array}{c}.952^{\star \star \star} \\
{[.872,1.03]}\end{array}$ & $\begin{array}{c}-.007^{\star \star \star} \\
{[-.008,-.005]}\end{array}$ & $\begin{array}{c}-.000 \\
{[-.000, .000]}\end{array}$ \\
\hline Vehicle Characteristics & Yes & Yes & Yes & Yes & Yes & Yes & Yes & Yes & Yes \\
\hline Model Fixed Effects & Yes & Yes & Yes & Yes & Yes & Yes & Yes & Yes & Yes \\
\hline Adjusted R-squared & .790 & - & 125 & .762 & - & 231 & .608 & - & .038 \\
\hline Number of Auctions (clusters) & $91996(976)$ & 91892 & $97701(978)$ & $65129(876)$ & 65024 & $78121(877)$ & 37662 (1059) & 37518 & 39022 (1063) \\
\hline
\end{tabular}




\section{Table A5: External Validity}

Non Parametric Regression Discontinuity Results

Bootstrapped standard errors in parentheses, based on 50 replications

Cat-C, Regime 1

Jumps up from 40 to 120 at $P A V=1500$

Last Regime

Jumps up from 5 to 160 at $P A V=2000$

(1) Comparison

(2) Baseline

(3) Assume RD at PAV $=1500$

\section{Outcome Variable}

\section{A. Winning Amount}

Implied $\Delta$ Outcome $/ \Delta \mathbf{R}$

B. Number of Bidders

Implied $\Delta$ Outcome $/ \Delta \mathbf{R}$

C. Vehicle Unsold [Yes =1]

Implied $\Delta$ Outcome $/ \Delta \mathbf{R}$

\section{$33.6^{\star \star \star}$}

$.420^{\star \star \star}$

$[.336, .504]$

$$
-1.33^{* \star *}
$$

$-.017^{\star * *}$

$[-.018,-.016]$

$.104^{\star * *}$

$.003^{\star * *}$

$[.003, .003]$

3.46

$138.8^{*}$

$.888^{*}$

$[-.156,1.93]$

$\begin{array}{ll}-.805 & -.013\end{array}$

56959

17410

17410

\section{Number of Auctions}

Notes: ${ }^{* * *}$ denotes significance at $1 \%,{ }^{* *}$ at $5 \%$, and ${ }^{*}$ at $10 \%$. All observations relate to auctions where there is at least one bidder. Each coefficient is estimated from a separate non parametric regression using a triangular kernel, where the bandwidth is set is chosen to give positive weight to at least 30 observations on each side of the discontinuity when estimating the conditional mean at the cut-off. Bootstrapped standard errors based on 50 replications are shown. A Category B Vehicle is a Salvaged Vehicle which is so structurally damaged or devoid of parts that it is not possible to repair it economically or safely. A Category C Vehicle is a Salvaged Vehicle which is damaged to the extent that the retail cost of repair to the vehicle exceeds the retail pre-accident value thereof. A Category D Vehicle is a Salvaged Vehicle which is damaged to the extent that the retail cost of repair to the vehicle does not exceed the retail pre-accident value thereof. Each Column represents a different regime in which the relationship between the pre-accident value (PAV) and the public reserve price $(\mathrm{R})$ varies. 
Table A6: Auction Outcome Descriptives, by Auction Number

\section{Category C Vehicles, Regime 1}

Means, standard deviation in parentheses

First Time Auction

(1) Vehicle Sold (2) Vehicle Unsold

Number of Auctions (\% of First/Second Time Auctions)

Reserve Price in First Time Auction

Reserve Price in Second Time Auction

56904 (95.9)

Winning Amount

Number of Bidders

Percentage of Auctions With One Bidder

Win Rate Among Bidders
Second Time Auction

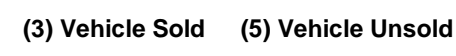

$1938(99.1)$

226

(250)

(287)

$17(.009)$

188

(144)
178

(243) 2439 (4.11)

5

(0)

$495 \quad-\quad 149$

(1037) (192)

$4.67 \quad 4.54$

(3.05)

$.070 \quad .010$

(.254)

$223-221$

(.082) t-test: Column 1=3 t-test: Column 2=4

(5) p-value (6) p-value

$[.000]$

Notes: All auctions refer to Category C vehicles during regime 1. A Category C Vehicle is a Salvaged Vehicle which is damaged to the extent that the retail cost of repair to the vehicle exceeds the retail pre-accident value thereof. The number of bids placed included proxy bids. In Columns 5 and 6 we report the p-value on a two-sided test of the null hypothesis that the means are equal across first and second time auctions. The win rate for any given bidder is the percentage 0

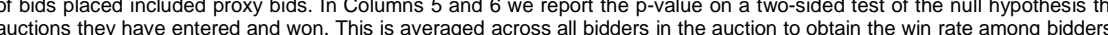


Table A7: Re-auction Outcomes

Dependent Variable: Winning Amounts in Re-auctions of Category C Regime 1 Vehicles Robust standard errors in parentheses clustered by auction closing date

(1) Unconditional

(2) Baseline

(3) Heterogeneous Effects of PAV

\begin{tabular}{|c|c|c|c|}
\hline Reserve Price in First Time Auction & $\begin{array}{l}.343^{\star \star *} \\
(.125)\end{array}$ & $\begin{array}{l}.359^{\star * *} \\
(.077)\end{array}$ & 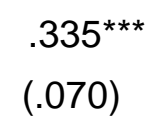 \\
\hline Log (Pre-accident Value) & & $\begin{array}{c}.031 \\
(.087)\end{array}$ & $\begin{array}{c}.024 \\
(.300)\end{array}$ \\
\hline Log (Pre-accident Value) $x \mid[P A V>=1500]$ & & & $\begin{array}{l}-.005 \\
(.288)\end{array}$ \\
\hline Implied Marginal Effect (on level of winning bid) & & $\begin{array}{l}.238^{\star * \star} \\
(.051)\end{array}$ & 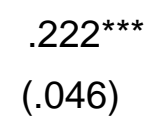 \\
\hline Other Vehicle Characteristics & No & Yes & Yes \\
\hline Month of Auction Dummies (39) & No & Yes & Yes \\
\hline Year of Manufacture Dummies (29) & No & Yes & Yes \\
\hline Salvage Yard Dummies (14) & No & Yes & Yes \\
\hline Model Fixed Effects & No & Yes & Yes \\
\hline Adjusted R-squared & .197 & .572 & .573 \\
\hline Number of Auctions & 1826 & 1826 & 1826 \\
\hline
\end{tabular}

Notes: ${ }^{* * *}$ denotes significance at $1 \%,{ }^{* *}$ at $5 \%$, and ${ }^{*}$ at $10 \%$. All observations relate to second auctions of category $\mathrm{C}$ Vehicles in Regime 1, where there is at least one bidder. The other vehicle characteristics controlled for in Columns 2 onwards are the number of days since the first auction, the indicated mileage, whether it runs on petrol, whether it is manual transmission, whether the keys are available, whether a service history is available, whether a V5 logbook is available, whether the vehicle is a EU import, the number of words describing vehicle damage, and a series of dummies for the year of manufacture, the salvage yard holding the vehicle, month of auction, and vehicle model effects. In Columns 2 and 3 all continuous variables are in logs. Robust standard errors that are clustered by auction opening date are estimated throughout. The marginal effect reported at the foot of the table is the implied effect on the level of the winning bid (not in logs). 
Figure 1: Regression Discontinuity Design and Outcomes 1A. Category C Vehicle Reserve Prices: Regime 1

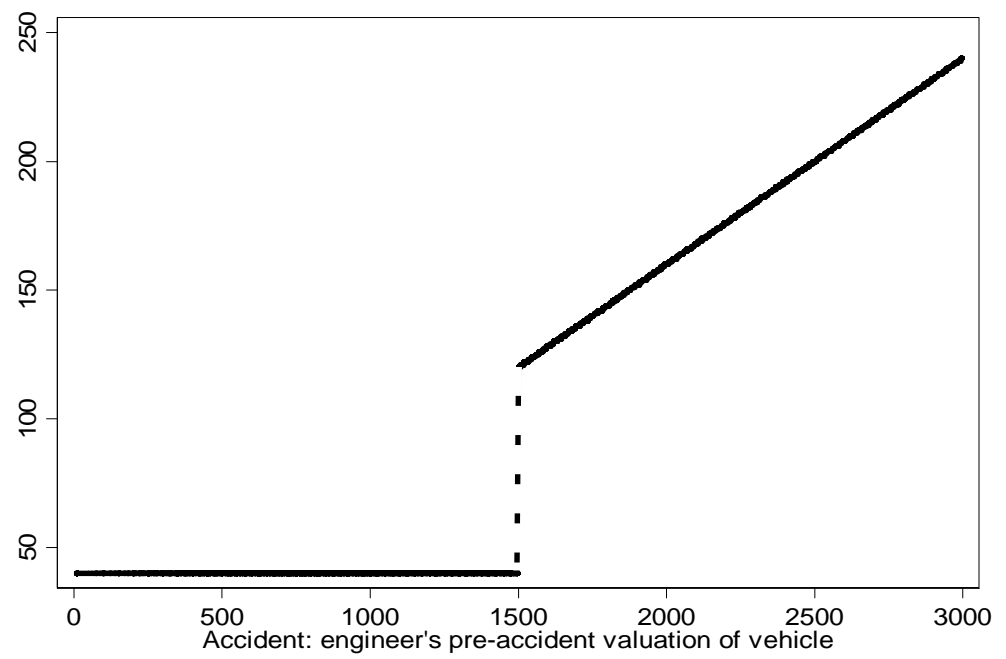

1B. Winning Amount by Assignment Variable for Category C Regime 1 Vehicles

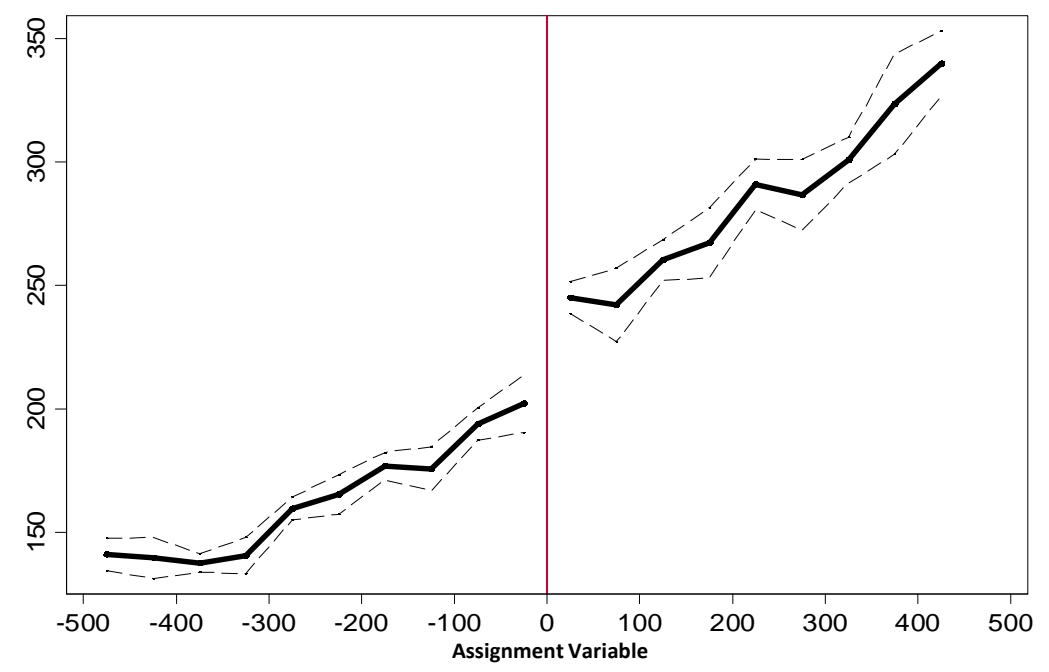

1C. Number of Bidders by Assignment Variable for Category C Regime 1 Vehicles

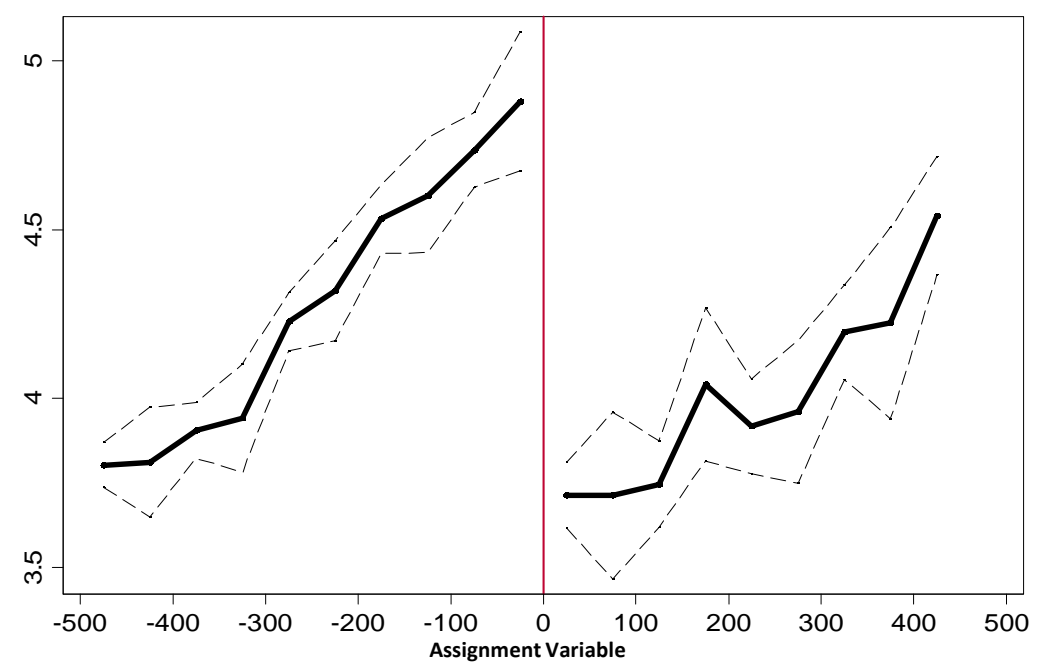

Notes: All figures use auction data from Category C vehicle auctions during regime 1, which is in place from July 10 th 2006 until November 17th 2008. Figure $1 \mathrm{~A}$ shows the relationship between the engineers pre accident valuation of the vehicle and its auction reserve price. Figures $1 \mathrm{~B}$ and $1 \mathrm{C}$ plot over bins of width 50 over the assignment variable, the average winning bid and the average number of bidders, respectively. These
averages are graphed at the mid point of each bin. In each Figure the average and its associated $95 \%$ confidence interval is shown in dashed lines. 


\section{Figure 2: Non Parametric Regression Discontinuity Estimates}

\section{A. Winning Amount by Assignment Variable for Category C Vehicles}

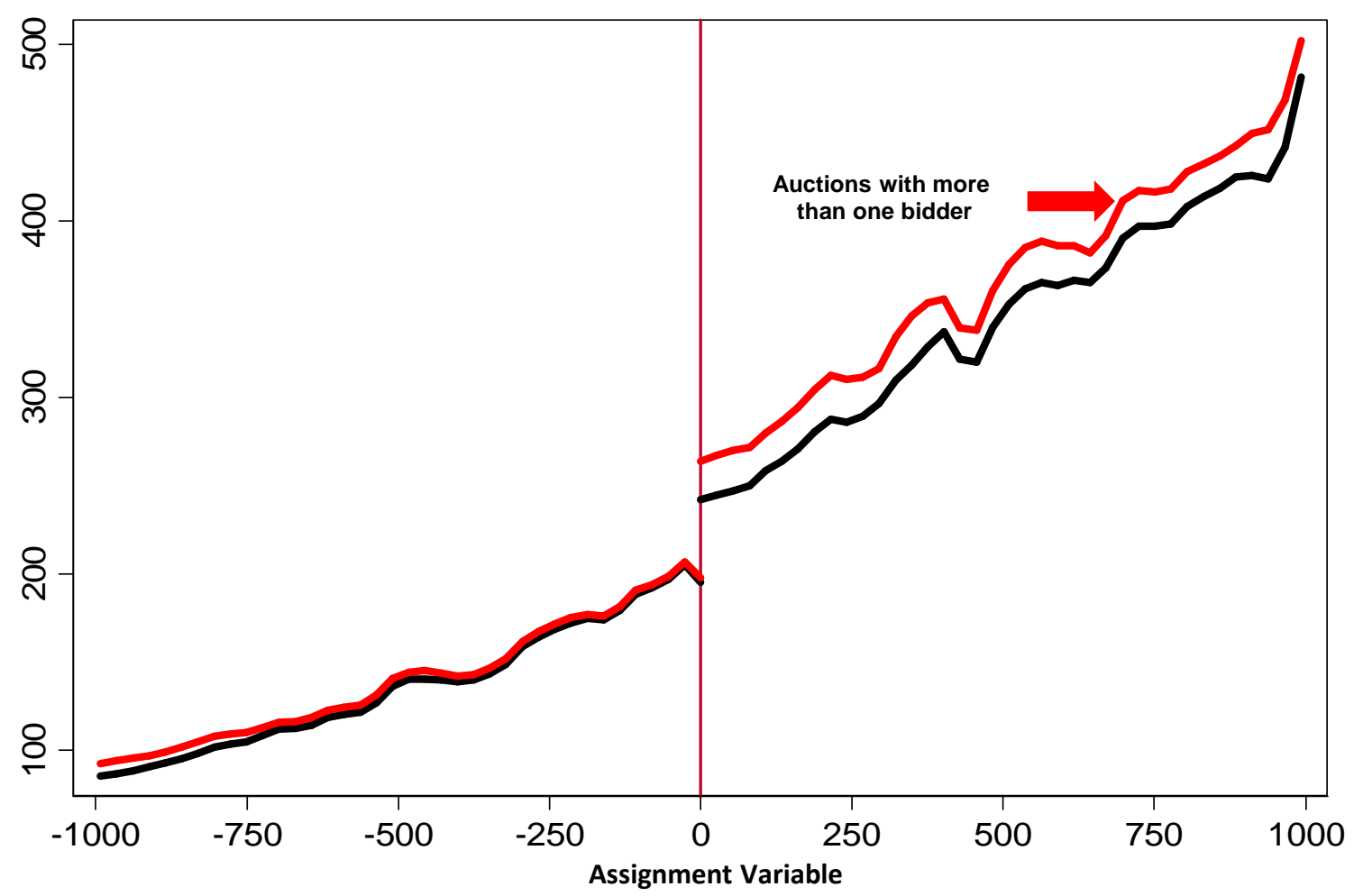

2B. Number of Bidders by Assignment Variable for Category C Vehicles

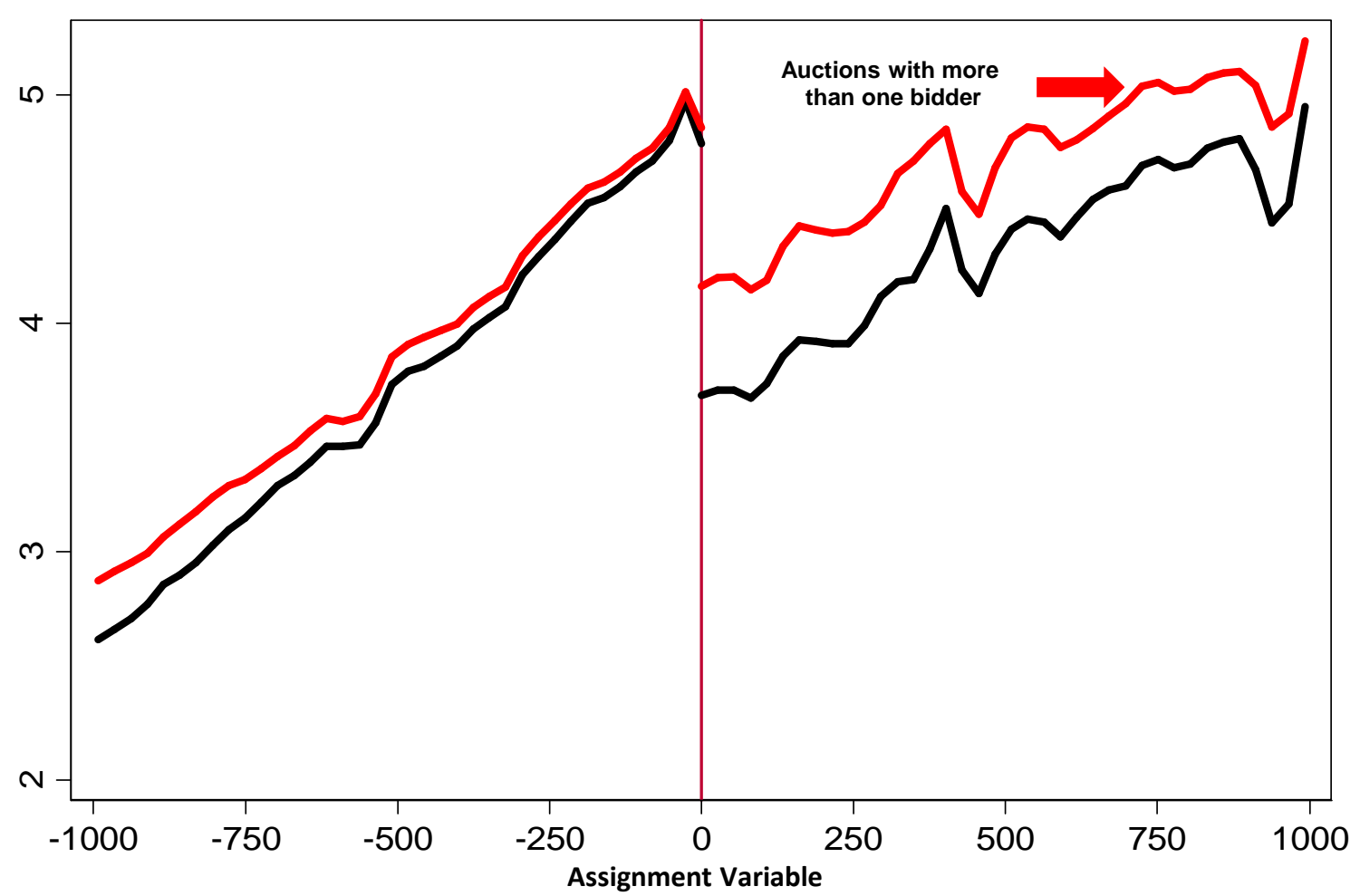

Notes: Both figures use auction data from Category $\mathrm{C}$ vehicle auctions during regime 1, which is in place from July 10 th 2006 until November 17 th 2008. The figures show the non-parametric estimates of how winning bids and the number of bidders vary with the reserve price effect at all values of the assignment variable from -1000 to +1000 . 
Figure A1: Regression Discontinuity Specification Checks

A1A. Residual for Winning Amount Around the Cut-off

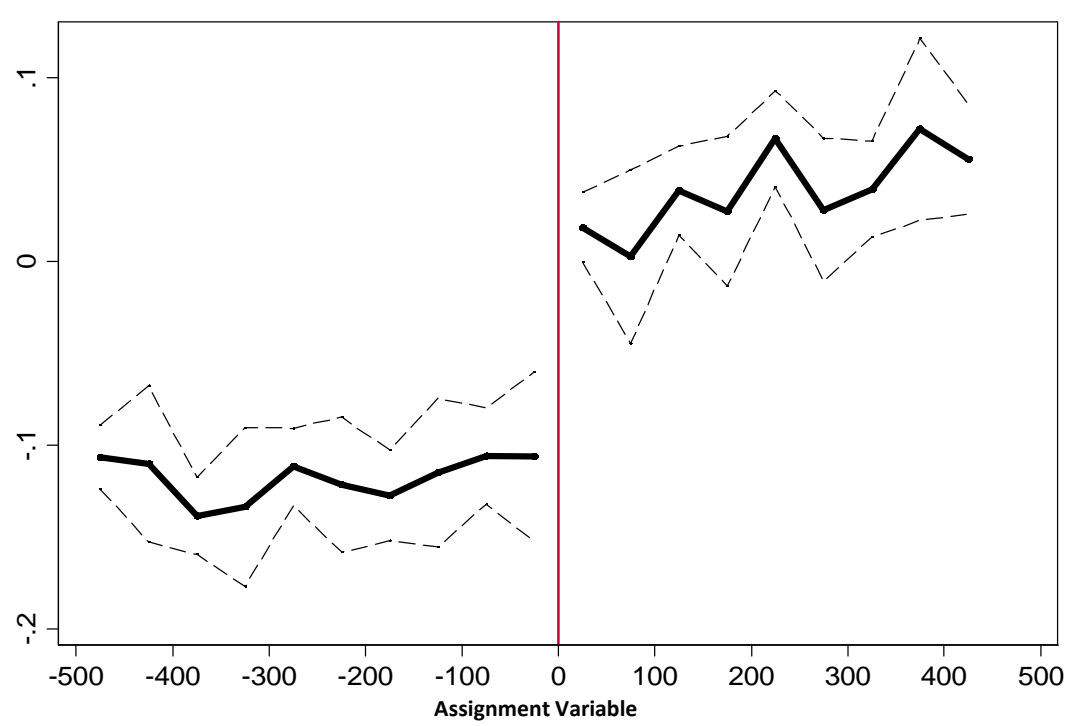

A1C. Smoothness of the Assignment Variable Around the Cut-off

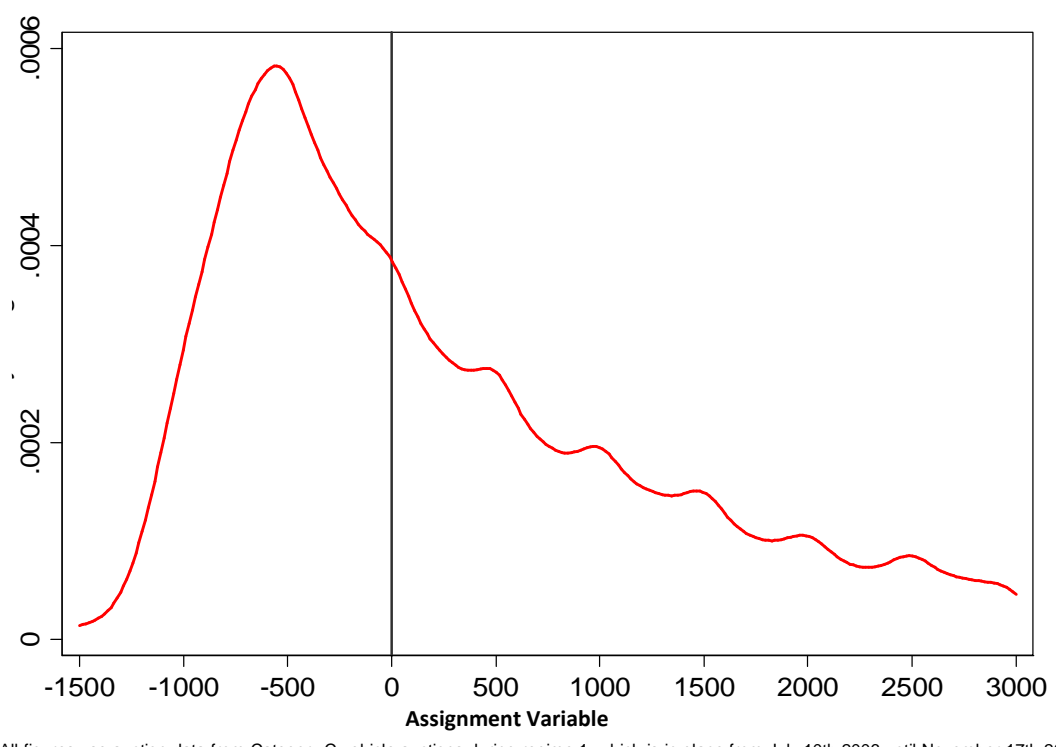

A1B. Predicted Number of Bidders Around the Cut-off

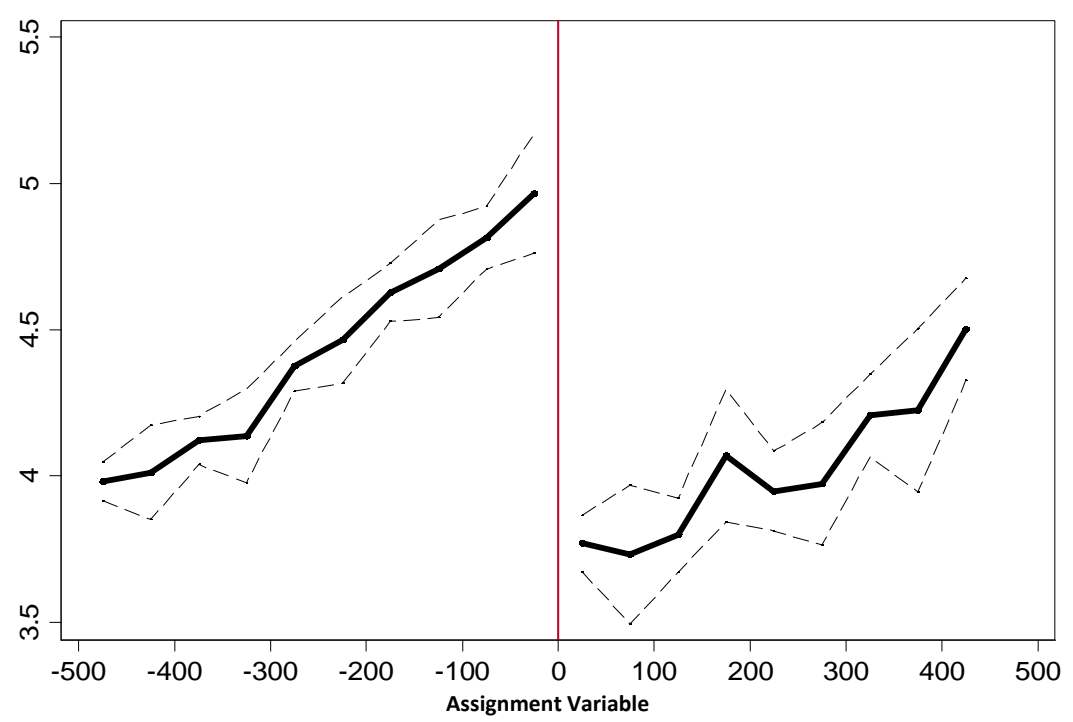

A1D. Win-rate of Auction Entrants Around the Cut-off

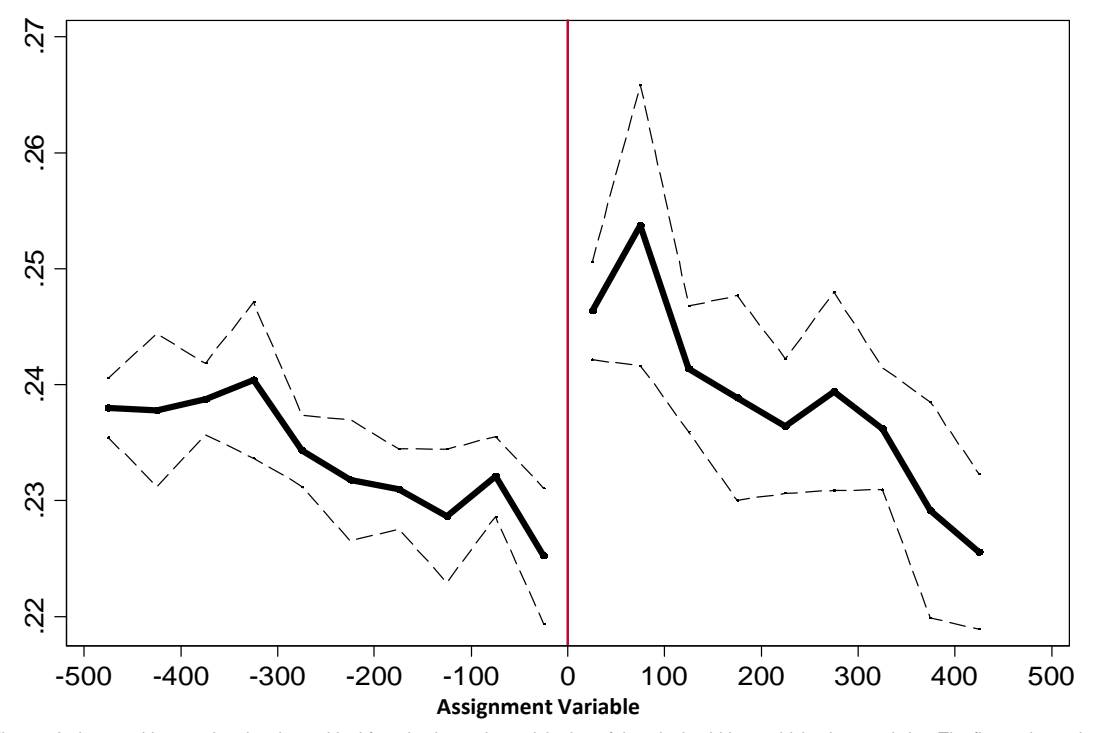

Notes: All figures use auction data from Category C vehicle auctions during regime 1, which is in place from July 10 th 2006 until November 17th 2008 . Figure 1 A shows evidence related to the residual from having estimated the log of the winning bid on vehicle characteristics. The figure shows the average residual, and its associated $95 \%$ confidence interval, in bins of width 50 either side of zero for the assignment variable over the range \pm 500 . Figure A1B shows analogous results based on the fixed effects Poisson regression for the number of bidders. Figure A1C shows the kernel density of
the assignment variable, (PAVi-500). The bandwidth chosen is Silverman's 1986$]$ optimal bandwidth. Figure A1D shows the average win rate of auction entrants, and its associated $95 \%$ confidence interval, in bins of width 50 either side of zero for the assignment variable over the range $+=-500$. 